\title{
HIV-1 dual/mixed tropic isolates show different genetic and phenotypic characteristics and response to maraviroc in vitro ${ }^{\text {is }}$
}

\author{
Valentina Svicher ${ }^{a}$, Emanuela Balestra ${ }^{a}$, Valeria Cento ${ }^{a}$, Loredana Sarmati ${ }^{b}$ Luca Dori $^{b}$, \\ Ina Vandenbroucke ${ }^{\mathrm{c}}$, Roberta D’Arrigo ${ }^{\mathrm{d}}$, Anna Rita Buonomini ${ }^{\mathrm{b}}$, Herwig Van Marck ${ }^{\mathrm{c}}$, \\ Matteo Surdo ${ }^{a}$, Patrizia Saccomandi ${ }^{a}$, Wendy Mostmans ${ }^{c}$, Jeroen Aerssens ${ }^{c}$, Stefano Aquaro ${ }^{\mathrm{a}, \mathrm{e}}$, \\ Lieven J. Stuyver ${ }^{c}$, Massimo Andreoni ${ }^{b}$, Francesca Ceccherini-Silberstein ${ }^{a, *}$, Carlo Federico Perno ${ }^{a, d}$ \\ a Department of Experimental Medicine, University of Rome Tor Vergata, Via Montpellier 1, 00133 Rome, Italy \\ ${ }^{\mathrm{b}}$ Clinic of Infectious Diseases, University of Rome Tor Vergata, Rome, Italy \\ c Virco BVBA, Beerse, Belgium \\ d National Institute for Infectious Diseases “L. Spallanzani”, Rome, Italy \\ e Faculty of Pharmacy, University of Calabria, Cosenza, Italy
}

\section{A R T I C L E I N F O}

\section{Article history:}

Received 3 November 2010

Accepted 16 February 2011

Available online $\mathrm{xxx}$

Keywords:

HIV-1 tropism

Maraviroc

Pyrosequencing

Phenotyping

Env mutations

\begin{abstract}
A B S T R A C T
Dual/mixed-tropic HIV-1 strains are predominant in a significative proportion of patients, though few information is available regarding the genetic characteristics, quasispecies composition, and susceptibility against CCR5-antagonists of the primary-isolates. For this reason, we investigated in deep details, both phenotypically and genotypically, the characteristics of 54 HIV-1 primary-isolates obtained from HIV-infected patients. Tropism was assessed by multiple-cycles phenotypic-assay on U87MG$\mathrm{CD}^{+}$-CCR5 ${ }^{+}-/ \mathrm{CXCR} 4^{+}$-expressing cells. In vitro selection in PBMCs of X4-tropic viral strains following maraviroc-treatment was also performed.

Phenotypic-assay reported pure R5-tropic viruses in 31 (57.4\%) isolates, dual/mixed-tropic viruses in 22 (40.7\%), and pure X4-tropic virus in only 1 (1.8\%). Among dual/mixed-tropic isolates, 12 showed a remarkably higher replication-efficacy in CCR5-expressing cells ( $\left.\mathrm{R}^{+} / \mathrm{X} 4\right)$, and 2 in CXCR4-expressing cells $\left(\mathrm{R} 5 / \mathrm{X}^{+}\right)$. Genotypic-tropism testing showed a correlation between PSSM-scores, geno2pheno false-positive-rate, and V3-net-charge with both CCR5-usage and syncytium-inducing ability. Moreover, specific gp120- and gp41-mutations were significantly associated with tropism and/or syncytiuminducing ability.

Ultra-deep V3-pyrosequencing showed the presence of a swarm of genetically distinct species with a preference for CCR5-coreceptor not only in all pure R5-isolates, but also in 6/7 R5 $/ \mathrm{X} 4$-tropic isolates. In both pure- $\mathrm{X} 4$ and $\mathrm{R} 5 / \mathrm{X}^{+}$-isolates, we observed extensive prevalence of $\mathrm{X} 4$-using species. In vitro selection-experiments with CCR5-inhibitor maraviroc (up to 2 months) showed no-emergence of X4tropic variants for all R5- and $\mathrm{R}^{+} / \mathrm{X} 4$-isolates tested (while X4-virus remained fully-resistant).

In conclusion, our study shows that dual/mixed-tropic viruses are constituted by different species, whereby those with characteristics $\mathrm{R}^{+} / \mathrm{X} 4$ are genotypically and phenotypically similar to the pure-R5 isolates; thus the use of CCR5-antagonists in patients with $\mathrm{R}^{+} / \mathrm{X} 4$-tropic viruses may be a therapeuticoption that deserves further investigations.
\end{abstract}

(c) 2011 Published by Elsevier B.V.

\section{Introduction}

HIV-1 entry into host cells requires gp120-interaction with CD4-receptor and then with either CCR5 or CXCR4 chemokine co-

\footnotetext{
This work has been presented in part at the 16th Conference on Retroviruses and Opportunistic Infections, Montreal, Canada, 8-11 February 2009, and at the 7th European HIV Drug Resistance Workshop, Stockholm, Sweden, 25-27 March 2009.

* Corresponding author. Tel.: +39 06 72596553; fax: +39 0672596039.
}

receptor. HIV-1 strains can be phenotypically classified according to virus-ability to use CCR5 and/or CXCR4 co-receptor. Thus, pure R5tropic and pure X4-tropic virus can use only the CCR5 and CXCR4 co-receptors to enter target-cell, respectively, while dual-tropic virus can use both co-receptors (Berger, 1998; Loftin et al., 2010; Scarlatti et al., 1997; Yi et al., 1999, 2005). In a viral population, the use of both co-receptors can be due either to the presence of dualtropic clones, to a mixture of pure R5-tropic and X4-tropic clones, or both. This is defined as dual/mixed (D/M) phenotype.

R5-tropic viruses are generally responsible for the establishment of the initial infection, and predominate in most drug-naïve 
patients (prevalence, >80\%) also in advanced stages of the disease (Brumme et al., 2005; Melby et al., 2006; Moyle et al., 2005; Wilkin et al., 2007), while X4-tropic viruses are restricted to advanced stages, and are associated with CD4-cell count decline. In addition, they are rarely observed in either drug naïve $(<1 \%)$ or treatment-experienced patients $(<5 \%)$ with preserved immunefunction (Brumme et al., 2005; Melby et al., 2006; Moyle et al., 2005; Wilkin et al., 2007; Simon et al., 2010). Conversely, a quite high proportion of patients harbouring dual/mixed-tropic viruses has been observed both in drug-naïve (prevalence ranging 12-15\%) and in treatment-experienced patients (prevalence ranging 20-50\%) (Church et al., 2008; Huang et al., 2007; Lihana et al., 2009; Moreno et al., 2009; Shepherd et al., 2008).

Preliminary findings recently highlighted the existence of different types of $\mathrm{D} / \mathrm{M}$ viruses: those that are much more efficient in using the CCR5 co-receptor $\left(\mathrm{R}^{+} / \mathrm{X} 4\right)$, those that use more efficiently the CXCR4 (R5/X4 $4^{+}$), and those that can use with the same efficiency both co-receptors (R5/X4) (Loftin et al., 2010; Huang et al., 2007; Symons et al., 2011; Toma et al., 2010). These studies have been conducted using recombinant viruses, while nothing is known about the tropism characteristics of primary HIV-1 isolates, and their pathogenetic potential.

CCR5-antagonists are a new class of anti-HIV-1 drugs that specifically inhibit the entry of CCR5-tropic HIV-1 strains into the target cells by allosteric inhibition of the CCR5 co-receptor (Dorr et al., 2005; Princen and Schols, 2005; Regoes and Bonhoeffer, 2005). Maraviroc is the first approved CCR5 antagonist, which entered in clinical practice in 2007. Although the use of maraviroc is so far recommended only in patients with pure R5-viruses (Department of Health and Human Services, 2009), there is the increasing evidence that the use of this drug may be productively extended also to a subset of patients harbouring D/M-tropic viruses (Symons et al., 2011; Toma et al., 2010; Swenson et al., 2009). Therefore, defining the subset of viruses that can be suppressed by maraviroc is crucial to optimize the use of CCR5 antagonists in clinical practice, also in patients infected with $\mathrm{D} / \mathrm{M}$ tropic viruses.

In this light, the goal of this study was to phenotypically and genotypically characterize the viral tropism of a large panel of HIV-1 primary isolates obtained from plasma of HIV-1 infected individuals. Particular attention was dedicated to: (a) the definition of R5-, X4-, D/M-populations by the study of viral replication in U87 cell lines expressing CXCR4 or CCR5 coreceptor; (b) fulllength gp160 standard population sequencing; (c) V3 ultra-deep pyrosequencing, and evaluation of in vitro selection of X4-tropic viral strains following maraviroc treatment.

\section{Materials and methods}

\subsection{Cells}

Human astroglioma U87MG-cells expressing CD4-receptor alone or with CXCR4 co-receptor (U87MG-CD4 $4^{+} / \mathrm{CXCR} 4^{+}$) or CCR5 co-receptor (U87MG-CD4 ${ }^{+} / \mathrm{CCR}^{+}$) and their corresponding parental cells were kindly provided by Dr. David Kabat, and were maintained in MEM/EBSS (Gibco) with the addition of $10 \%$ fetal bovine serum (FBS-HiClone), $1 \mathrm{mM}$ sodium pyruvate (Euroclone), $0.1 \mathrm{mM}$ non-essential amino acids (Euroclone), $100 \mathrm{U} / \mathrm{ml}$ penicillin $+100 \mu \mathrm{g} / \mathrm{ml}$ streptomycin (Euroclone) and $2 \mathrm{mM} \mathrm{L-glutamine} \mathrm{(Gibco).} \mathrm{Medium} \mathrm{for} \mathrm{U87MG-CD4}{ }^{+} / \mathrm{CXCR}^{+}$ and U87MG-CD4 ${ }^{+} / \mathrm{CCR}^{+}$was supplemented with $400 \mu \mathrm{g} / \mathrm{ml} \mathrm{G418}$ (Sigma-Chemicals). Peripheral blood mononuclear cells (PBMC) were obtained by centrifuging whole-blood from healthy HIVseronegative blood-donors on a Ficoll-Hypaque density-gradient as previously described (Aquaro et al., 2001, 2004; Garaci et al., 2003;
Perno et al., 1998). MT-2 cell-line expressing CD4- and CXCR4receptors were maintained in RPMI1640 (Euroclone) with addition of $10 \% \mathrm{FBS}$ at $37^{\circ} \mathrm{C}$ with $5 \% \mathrm{CO}_{2}$.

\subsection{Viruses}

Seventy-one isolates were obtained from $\mathrm{CD}^{+}$-depleted PBMC of HAART-experienced HIV-infected patients, after achievement of therapeutic-success, as previously described (Andreoni et al., 2000). The laboratory strains $\mathrm{HIV}_{\mathrm{BaL}}$ (pure R5-tropic) and $\mathrm{HIV}_{\mathrm{IIIB}}$ (pure X4-tropic) were used as controls in all in vitro experiments.

\subsection{Phenotypic-tropism}

Viral tropism was evaluated by a phenotypic assay based on multiple cycles of replication in $\mathrm{U} 87 \mathrm{MG}-\mathrm{CD} 4^{+} / \mathrm{CCR}^{+}$and U87MG-CD4 ${ }^{+} / \mathrm{CXCR}^{+}$cells. Briefly, U87MG-CD4 ${ }^{+} / \mathrm{CCR}^{+}$and

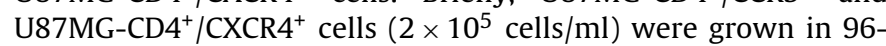
well plates in a final volume of $200 \mu \mathrm{l} /$ well. After $24 \mathrm{~h}$, the medium was removed, and the infection was performed by using $100 \mu \mathrm{l} /$ well of viral suspension $\left(900 \mathrm{TCID}_{50} / \mathrm{ml}\right)$ for $2 \mathrm{~h}$. The test was performed in quadruplicate. After 13 days of culture, the supernatants were collected and analyzed for $\mathrm{p} 24$ production (AgGenscreen TM HIV-1 Assay, BioRad) to a dilution up to 1:100 to better quantify viral production.

\subsection{Syncytia-phenotypic assay}

To determine the syncytium-inducing or non-syncytiuminducing biological phenotype of HIV-1 isolates, an aliquot of viral-stock supernatant containing $100 \mathrm{TCID}_{50} / \mathrm{ml}$ (tissue culture infectious doses) was cultured in T25 flasks with $10^{6}$ MT-2-cells. Cultures were maintained up to 4-weeks and examined for syncytia twice a week. Syncytia formation was defined as at least 10 multinucleated giant cells in 5-high-power fields

\subsection{In vitro selection of X4-tropic viral strains following maraviroc treatment}

Maraviroc was used at the concentrations of $200 \mathrm{nM}$ and $40 \mathrm{nM}$, about 100 and 20 times higher than $\mathrm{IC}_{90}$, respectively, as previously determined in an in vitro study (Dorr et al., 2005), and in the range of Cmin of maraviroc in treated patients $(74 \mathrm{nM}=37.2 \mathrm{ng} / \mathrm{ml}$, http://us.gsk.com/products/assets/us_selzentry.pdf). Zidovudine (AZT) was used as control at a concentration of $1 \mu \mathrm{M}$, known to inhibit $>99 \%$ the replication of laboratory strains. Stimulated PBMC with IL-2 and PHA were infected with a standardized input of each virus $(12,000 \mathrm{p} 24 \mathrm{pg} / \mathrm{ml})$. After $2 \mathrm{~h}$ of adsorption, cells were extensively washed to remove any residual viral particle, re-suspended in complete medium and cultured on 96-well plates (20,000 cells/well) for 3 days. These cultures were then used to infect fresh activated PBMC by co-cultivation in presence of maraviroc (at concentration of $40 \mathrm{nM}$ and/or $200 \mathrm{nM}$ ). After 3 days, the co-cultivated cells were transferred into 48 -well culture plates. The cultures were split weekly and renewed by adding fresh stimulated PBMC (total cell density, $4 \times 10^{5} / \mathrm{ml}$ ). Maraviroc was added at the start of each new co-culture, and always maintained at the same concentrations as at the beginning of the experiment. Experiments were continued up to 7 co-cultures ( 2 months). Virus-growth was monitored weekly by measuring supernatant p24 levels, before starting a new co-culture. All assays were performed in duplicate. For each isolate, infected-PBMC were also kept untreated, as a control of viral replication without drug-pressure. 


\subsection{Gp160 sequencing}

The protocol for full-length GP160 sequencing has been designed and optimized as follows. HIV-1 RNA was extracted from each isolate with a commercially available kit (QIAamp RNA-Viral-Mini-kit, Qiagen). The full-length HIV1 gp160 region of env gene was then reverse-transcribed and amplified by two overlapping polymerase chain reactions (PCR) using two couples of primers (amplicon$\mathrm{A}=\mathrm{S} 1: 5^{\prime}$ GATGGAACAAGCCCCAGAA3' + AS4:5' GGGAGGGGCATACATTGCT3' and amplicon-B = S10: 5'CCAATTCCCATACATTATTGT3' + AS9:5'GTCCCCCCTTTTCTTTTAAAA3'). The conditions for reverse transcription and amplification were: one cycle at $50{ }^{\circ} \mathrm{C}$ for $30 \mathrm{~min}$, one cycle $94^{\circ} \mathrm{C}$ for $2 \mathrm{~min}, 40$ cycles $\left(94^{\circ} \mathrm{C} 30 \mathrm{~s}, 53^{\circ} \mathrm{C}\right.$ $30 \mathrm{~s}, 72^{\circ} \mathrm{C} 2 \mathrm{~min}$ ), and a final step at $72^{\circ} \mathrm{C}$ for $10 \mathrm{~min}$, using the following reaction mix: $25 \mu$ l of RNA template, $8 \mu$ l of $5 \mathrm{mM} \mathrm{Mg}{ }^{2+}, 3 \mu \mathrm{l}$ of Dnase Rnase free water, $0.75 \mu \mathrm{l}$ of each primer at a concentration of $10 \mu \mathrm{M}, 1 \mu \mathrm{l}$ of Rnase out $(40 \mathrm{U} / \mu \mathrm{l})$, $1.5 \mu \mathrm{l}$ of RT/Taq, $1 \mu \mathrm{l}$ of dNTPs at a concentration of $10 \mathrm{mM}$ for a total of $40 \mu \mathrm{l}$. When the RT-PCR product was not visible on agarose gel, a nested PCR was performed (ampliconA = SNEW:5' GAAGCTGTTAGACATTTT3' + AS4:5'GGGAGGGGCATACATTGCT3' and amplicon-B = S10:5'CCAATTCCCATACATTATTGT3' + AMPB2AS: 5'CTTAAAGGTACCTGAGGTCT3'). Amplification conditions were: one cycle at $93^{\circ} \mathrm{C}$ for $12 \mathrm{~min}, 40$ cycles $\left(95^{\circ} \mathrm{C} 30 \mathrm{~s}\right.$, $51{ }^{\circ} \mathrm{C} 30 \mathrm{~s}, 72^{\circ} \mathrm{C} 2.2 \mathrm{~min}$ ) and a final step at $72{ }^{\circ} \mathrm{C}$ for $10 \mathrm{~min}$, using the following reaction mix: $5 \mu$ l of buffer taq $10 \times, 4 \mu \mathrm{l}$ of $\mathrm{Mg}^{2+}$ at a concentration of $25 \mathrm{mM}, 32.5 \mu \mathrm{l}$ of Dnase Rnase free water, $0.9 \mu \mathrm{l}$ of each primer at a concentration of $10 \mu \mathrm{M}, 1 \mu \mathrm{l}$ of dNTPs at a concentration of $10 \mathrm{mM}, 0.7 \mu \mathrm{l}$ of Taq $(5 \mu / \mu \mathrm{l})$ for a total of $45 \mu \mathrm{l}$. The PCR product was purified by Microcon PCR purification kit (Millipore). Negative and positive control samples were included in each PCR run to exclude false-positive and false-negative reactions.

PCR-products were then sequenced by using the BigDye terminator v.3.1 cycle sequencing kit (Applied-Biosystems), and an automated sequencer (ABI-3100). Several different overlapping sequence-specific primers were used to ensure the coverage of the gp160-sequence by at least two sequence segments (for amplicon-A, S2:5'GAAAGAGCAGAAGACAGTG3', S3:5'CCAATTCC CATACATTATTGT3', AS2:5'GTGTACATTGTACTGTGCTGA3', AS3: 5'CAATTTCTGGG TCCCCTC3', AS4:5'GAAAAATTCCCCTCCACAATT3', S4:5'CCAATTCCCATACATTATTG T3', AS4:5'CCCCTCCACAATTAAAA3'; for amplicon-B, S6:5'CTGACGGTACAGGCCAGA3', AS6: 5'GAGTATCCCTGCCTAACT3', S7:5'GGCTGTGGTATATAAAAATAT3', AS7:5'GTC CCCCCTTTTCTTTTAAAA3'). The sequences were analyzed using SeqScape-v.2.5 software. The quality endpoint for each individual, was ensured by a coverage of the entire gp 160 sequence by at least two sequence segments. Translated protein sequences from gp120- and gp41-genes were generated and aligned using Bioedit 7.0 software and CLUSTALW1.8. To ensure the quality of the data, sequences were excluded from the analysis if (a) contained stop codons; (b) contained ambiguities consisting of $>2$ bases per nucleotide position. Alignment of sequences was performed either globally on the full length gp120-gp41 genes, and for the specific protein. Furthermore, to facilitate gp120 analysis, different datasets were created containing either costant or variable gp120 domains.

The absence of cross-contamination was ensured through phylogenetic analysis of the obtained sequences. Phylogenetic trees were generated using GTR Model of substitution with both NJ and Maximum Likelihood (ML) tree building methods. The best fitting nucleotide substitution model was tested with the Hierarchical Likelihood Ratio Test (HLRT) implemented in the Model Test V3.0 software (Posada and Crandall, 1998). The statistical robustness within each phylogenetic tree was confirmed with a bootstrap analysis using 1000 replicates for the Neighbor-Joining (NJ) tree. All calculations were performed with PAUP* $4.0 \mathrm{~b} 10$ (http://paup.csit.fsu.edu/about.html) software. Gp120- and gp41sequences have been submitted to GenBank (accession numbers: HQ678249-HQ678297).

\subsection{V3 loop massively parallel sequencing}

Ultra-deep pyrosequencing (UDPS) was carried out with the 454 Life-Sciences platform (GS-FLX, Roche Applied-Science) on 17 isolates phenotypically characterized on U87MG-cells following previously published procedure (Parameswaran et al., 2007; Polz and Cavanaugh, 1998; Vandenbroucke et al., 2008, 2010). Briefly, viral RNA was extracted from $1 \mathrm{ml}$ of viral isolate (BioRobot MDx, Qiagen, Hilden, Germany), and reversely transcribed to cDNA. The V3 loop region was amplified in a nested PCR using barcoded primers (HXB2 positions: forward primer 6986-7012, reverse primer 7520-7540). Addition of barcode sequences to the primers allowed the simultaneous processing of amplicons originating from multiple individuals, enlarging the number of reads obtained per sequencing experiment. To maximize the number of input templates and to minimize variation due to PCR drift, 7 parallel RT-PCR reactions were performed. Barcoded amplicons were equimolar pooled and sequenced on the GS-FLX instrument according to manufacturer's amplicon sequencing protocol (454 Life Sciences, Roche Applied Science).

The frequency and distribution of errors introduced during V3 amplification and GS-FLX sequencing was assessed by analyzing data from amplicon sequencing of 2 plasmids in duplicate as previously reported (REF). Briefly, all detected changes relative to the published plasmid sequence were considered to be technical artefacts. An amplicon (in duplicate) covering the V3-region of HIV was created from plasmid pHXB2 [GenBank:K03455] and pYKJRSCF [GenBank:AY426126]. V3 amplicons were sequenced using the Standard GS-FLX amplicon sequencing protocol. The error rate was defined as the number of errors divided by the total number of expected bases. Homopolymeric regions were defined as regions containing repeats of three or more identical bases and the flanking non-identical bases. Data were retrieved from the Amplicon Variant Analysis software (Roche) with an average coverage of 20.000 reads per position. An overall error rate of $0.10 \%$ and $0.08 \%$ was obtained for pHXB2 and pYK-JRCSF, respectively. In addition, the error rate was elevated in homopolymeric regions: $0.13 \% \mathrm{vs}$. $0.07 \%$ in non-homopolymeric regions. Among the observed errors, deletions ( $\sim 40 \%)$ and insertions ( $\sim 33 \%)$ were the most frequent error types, followed by substitutions ( $\sim 26 \%$ ). The maximum substitution error rate per base position was $0.13 \%$, transitions from A to $G$ were most common, but also $T$ to $C$, $G$ to $C$, and $C$ to $G$ were frequently seen. A similarity was noted in frequency errors between duplicates, whereas differences between the two plasmids could be explained by sequence context. Therefore, mutations were accepted as real variants when present at a frequency above $0.5 \%$ of the total number of reads. In cases when the total number of reads was falling below 5000, a fixed cut-off of 50 reads was used.

\subsection{Computational methods}

The gp120-derived V3-fragment was used to infer viral tropism using PSSM (set at a cutoff of -5.96) and geno2pheno (set at a false positive rate [FPR] of 10\%) algorithms. Nglycosylation was predicted using the algorithm available at http://www.hiv.lanl.gov/content/sequence/GLYCOSITE/glycosite. html, while the V3 net-charge was calculated using the algorithm available at http://www.innovagen.se/custom- 

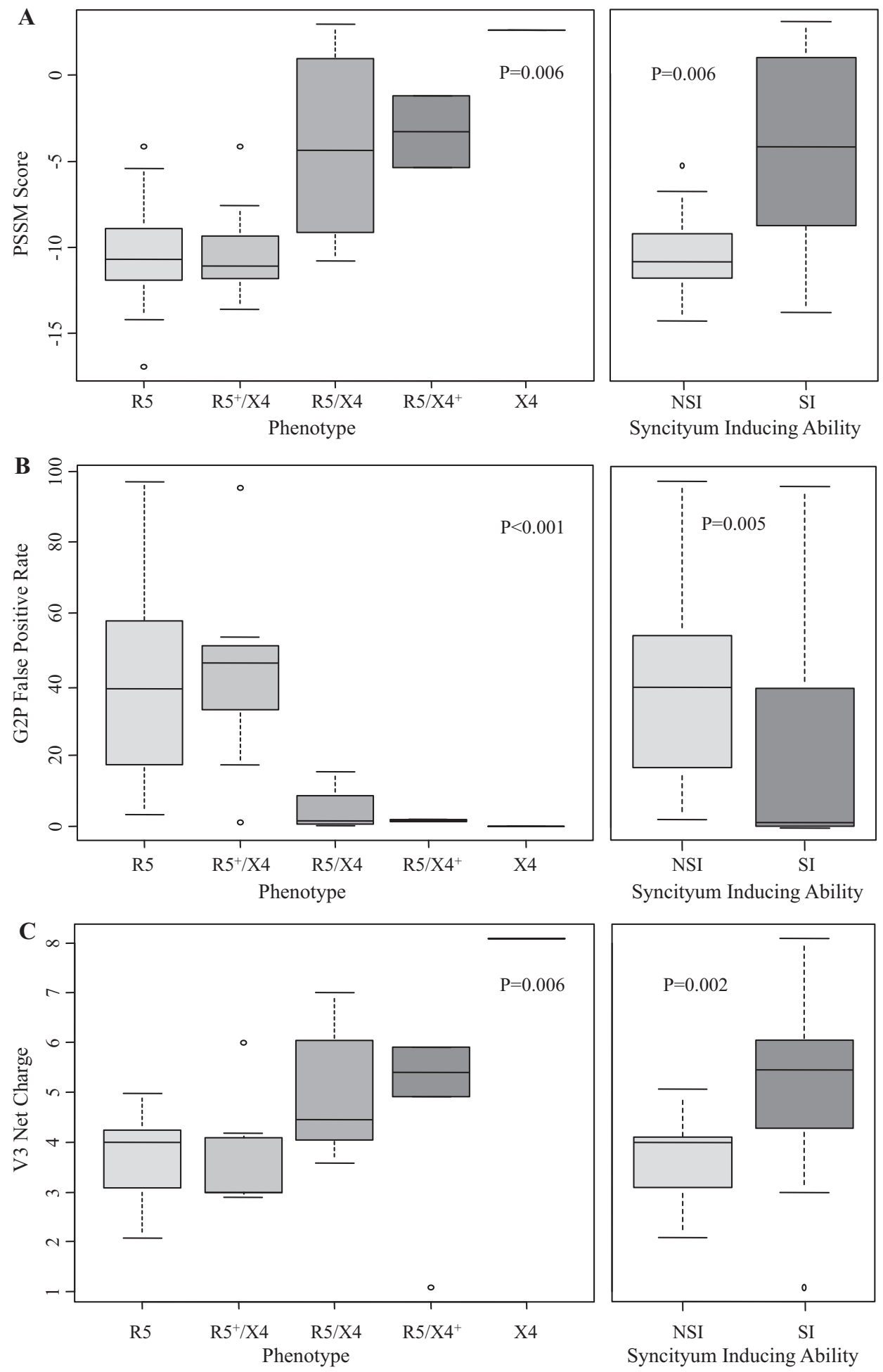

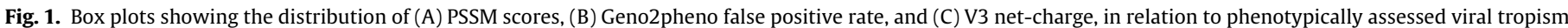
and syncytium-inducing ability. $P$-values were calculated by Kruskal-Wallis one-way analysis of variance by ranks test.

peptide-synthesis/peptide-property-calculator/peptide-propertycalculator.asp. This algorithm includes all the amino acids (arginine, aspartic acid, cysteine, glutamic acid, histidine, lysine, and tyrosine) generally recognized to contribute to the net charge of a specific peptide or protein Such algorithm has been also used to determine V3 net charge in other papers such as in Clevestig et al. (2006).
V3 sequences carrying nucleotide mixtures were translated into all possible amino acid permutations. For each combination, viral tropism and net charge have been determined. The isolate was defined as CXCR4-using if at least one combination showed an X4 predicted tropism. The final value of the $\mathrm{V} 3$ net-charge in presence of sequences' ambiguities was calculated as the median of the all possible values for each expanded sequence. 
Table 1

Patients characteristics.

\begin{tabular}{ll}
\hline Characteristics & \\
\hline Patients, $N$ & 71 \\
Patients with HIV-RNA <50 copies/ml, $N(\%)$ & $65(91.6)$ \\
CD4 cell count (cells/ $\mu \mathrm{l})$, median[IQR] & $801[636-959]$ \\
CD4 cell percentage $(\%)$, median[IQR] & $34.3[28.8-39.6]$ \\
Year from first positivity, median[IQR] & $8[6.8-14.5]$ \\
Therapy length (months), median[IQR] & $48.5[24.8-74]$ \\
\hline
\end{tabular}

IQR, interquartile range.

\subsection{Statistical analysis}

Kruskal-Wallis test (a non-parametric rank-based method) was used to assess statistically significant differences in the median PSSM-score, geno2pheno FPR, and V3 net-charge among viral isolates with different phenotypically assessed tropism and syncytium-inducing ability. Statistically significant differences in the prevalence of gp120-mutations among the different groups of isolates were assessed by Fisher-exact test. Mann-Whitney test was used to compare $\mathrm{p} 24$ production in $\mathrm{U} 87 \mathrm{MG}-\mathrm{CD} 4^{+} / \mathrm{CCR} 5^{+}$cells and U87MG-CD4 ${ }^{+} / \mathrm{CXCR}^{+}$cells.

\section{Results}

\subsection{Phenotypic characterization of primary HIV-1 isolates}

This study included 71 primary viral-isolates obtained from 71 HAART-treated patients. Their characteristics are reported in Table 1. These isolates were used to infect both U87MG$\mathrm{CD}^{+} / \mathrm{CCR}^{+}$and U87MG-CD4 ${ }^{+} / \mathrm{CXCR} 4^{+}$cells. Viral infection was evaluated by p24-quantification in culture supernatants. Tropism of 54 out of 71 (76.1\%) isolates was successfully characterized in indicator-cells. For the remaining 17 isolates, whose initial $\mathrm{TCID}_{50}$ were very low, viral-replication was not observed either in U87MG-CD4 ${ }^{+} / \mathrm{CCR}^{+}$cells or in U87MG$\mathrm{CD}^{+} / \mathrm{CXCR}^{+}$cells

Thirty-one (57.4\%) out of 54 isolates replicated only in U87MG$\mathrm{CD}^{+} / \mathrm{CCR}^{+}$cells, thus showing a pure $\mathrm{R} 5$-tropism, while 1 isolate $(1.8 \%)$ replicated only in $\mathrm{U} 87 \mathrm{MG}-\mathrm{CD} 4^{+} / \mathrm{CXCR} 4^{+}$cells, showing a pure X4-tropism. The remaining $22(40.7 \%)$ isolates replicated in both cell-lines, and thus were defined as D/M-tropic (Table 2 ). These isolates were further categorized according to the different p24 production observed in CCR5-expressing or CXCR4-expressing cells. In particular, 8 isolates replicated with the same efficiency in both cell-lines, showing a p24 production within the same range in the supernatants of either U87MG-CD4 ${ }^{+} / \mathrm{CCR}^{+}$or U87MG$\mathrm{CD} 4^{+} / \mathrm{CXCR}^{+}$cells $(P=0.625)$ (Table 2$)$. These isolates were defined as R5/X4-tropic viruses. For other 12 isolates, p24 production was far higher in $\mathrm{U} 87 \mathrm{MG}-\mathrm{CD} 4^{+} / \mathrm{CCR}^{+}$cells (median $\mathrm{p} 24$ production $>20,000 \mathrm{pg} / \mathrm{ml}$ ), than in U87MG-CD4 ${ }^{+} /$CXCR4 ${ }^{+}$cells (median $\mathrm{p} 24$ production $=49.6 \mathrm{pg} / \mathrm{ml}$; IQR $=29.9-139.9)(P=0.006)$; they were then defined as $\mathrm{R}^{+} / \mathrm{X} 4$-tropic viruses. For the last 2 isolates, p24 production was higher in U87MG-CD $4^{+} / \mathrm{CXCR} 4^{+}$cells (p24 production around $2000 \mathrm{pg} / \mathrm{ml}$ for both isolates), than in U87MG-CD4 ${ }^{+} / \mathrm{CCR}^{+}$cells $(\mathrm{p} 24$ production $=27.5$ and $94.1 \mathrm{pg} / \mathrm{ml}$, respectively) and they were defined as $\mathrm{R} 5 / \mathrm{X}^{+}$-tropic viruses. Thus, these results show a preferential co-receptor usage in a considerable fraction of D/M-tropic strains (14/22, 63.6\%) (Table 2).

For 47 out of 54 isolates (87\%), it was possible to analyze the ability of inducing syncytia in MT2-cells. Among 24 pure R5-tropic isolates analyzed, a syncytium-inducing phenotype was observed only in 1 isolate (4.2\%). The percentage of syncytia-inducing isolates progressively increased in $\mathrm{R}^{+} / \mathrm{X} 4$ (4/12 isolates, 33\%), and $\mathrm{R} 5 / \mathrm{X} 4$ isolates $(4 / 8$ isolates, $50 \%)\left(P_{\text {trend }}=0.012\right)$. A syncytium-inducing phenotype was then observed in both $\mathrm{R} 5 / \mathrm{X} 4^{+}$-tropic isolates available, as well as in the pure X4-tropic isolate (Table 2).

\subsection{Characterization of the env-gene obtained from population based sequencing}

The full-length gp120 and gp41 were successfully sequenced for 49 (gp120) and 36 (gp41) out of 54 (90.7\% and 67\%, respectively) primary isolates phenotypically characterized for viral tropism in indicator cells. Genotypic prediction of viral tropism using geno2pheno (set at FPR $=10 \%$ ) and PSSM algorithms (set at -5.96 cut-off) was $89.1 \%$ concordant with phenotypic tests performed on U87MG-cells. Geno2pheno and PSSM algorithms were 90.7\% each other concordant (Table 2).

A detailed analysis showed that PSSM scores and geno2pheno FPRs varied according to CCR5-usage potential. Indeed, we found a very similar PSSM low-score in pure $\mathrm{R} 5$ - and $\mathrm{R}^{+} / \mathrm{X} 4$-isolates (median $[\mathrm{IQR}]=-10.7[-11.9 ;-9.1]$ and $-11.1[-11.8 ;-9.3]$, respectively), while the highest PSSM values were observed for the pure $\mathrm{X} 4$-tropic isolate (+2.6); dual $\mathrm{R} 5 / \mathrm{X} 4$ and $\mathrm{R} 5 / \mathrm{X}^{+}$isolates showed a similarly high PSSM scores (median $[\mathrm{IQR}]=-4.4[-9.1 ;-0.9]$ and $-3.3[-4.3 ;-2.2$ ], respectively; $P=0.006$ ) (Fig. $1 \mathrm{~A}$ ). A similar correlation was observed for the geno2pheno-FPR (Fig. 1B). Indeed, higher FPRs were observed for the pure R5- and $\mathrm{R}^{+} / \mathrm{X} 4$-isolates (median[IQR] = 38.9[17.9-55.8] and 46.0[32.8-50.8], respectively), while lower FPRs were associated with $\mathrm{R} 5 / \mathrm{X} 4$ and $\mathrm{R} 5 / \mathrm{X}^{+}$isolates (median $[\mathrm{IQR}]=3.4[1.0-14.9]$ and $1.5[1.3-1.6]$, respectively) and the pure $\mathrm{X} 4$ isolate $(0.1)(P<0.001)$.

A correlation was also found between the V3 net-charge and CCR5-usage (Fig. 1C and Table 2). V3 net-charges were the lowest for pure-R5, and $\mathrm{R}^{+} / \mathrm{X} 4$ isolates (median $[\mathrm{IQR}]=4.0[3.1-4.2]$ and 3.0[3.0-4.1], respectively), while progressively increased in R5/X4, $\mathrm{R} 5 / \mathrm{X}^{+}$isolates (median[IQR] $=4.5[4.1-6.0]$ and 5.4[5.2-5.7], respectively), and in the pure-X4 isolate $(8.1)(P<0.01)$.

Similarly, the PSSM scores, geno2pheno FPR and V3 net-charge were also associated with the syncytium-inducing ability in MT2cells $(P<0.01)$ (Fig. 1$)$.

The analysis of positions 11,24 , and 25 (known to be important for co-receptor binding) revealed the presence of negative/neutral charges at positions $11,24,25$ in 24/28 (85.7\%) pure-R5 isolates, and in $15 / 20$ (75.0\%) D/M isolates (11/11 for $\mathrm{R}^{+} / \mathrm{X} 4,4 / 7 \mathrm{R} 5 / \mathrm{X} 4,0 / 2$ $\mathrm{R} 5 / \mathrm{X}^{+}$) (Table 3 ).

Taken together, results suggest a substantial homology between pure $\mathrm{R} 5$ - and $\mathrm{R}^{+} / \mathrm{X} 4$-isolates, at both genotypic and phenotypic level of analysis.

To better characterize D/M-tropic isolates, gp120- and gp41genotypic analysis was also performed. Specific gp120 variations, localized outside the V3 loop, as well as gp41 mutations significantly correlated with different co-receptor usage and syncytium-inducing ability. In particular, Y33H in gp120 and L244I in gp41 were found statistically associated with both D/Mphenotype and syncytium-inducing ability (Table 4).

\subsection{Characterization of V3-loop by UDPS}

Six pure-R5 isolates, the single pure- $\mathrm{X} 4$ isolate, and 10 randomly selected $\mathrm{D} / \mathrm{M}$ isolates $\left(7 \mathrm{R}^{+} / \mathrm{X} 4,1 \mathrm{R} 5 / \mathrm{X} 4\right.$, and $2 \mathrm{R} 5 / \mathrm{X} 4^{+}$) were analyzed by V3 UDPS (Fig. 2)

All 6 pure-R5 isolates and 5 out of 7 (71.4\%) $\mathrm{R} 5^{+} / \mathrm{X} 4$ isolates analyzed were composed by a swarm of distinct species, all $(100 \%)$ with a preference for CCR5 co-receptor, and associated with a narrow range of highly-negative PSSM scores (median[IQR] $=-11.9[-12.7 ;-10.9]$ and $-10.5[-11.9 ;-8.6]$, respectively) (Fig. 2). Two phenotypically $\mathrm{R}^{+} / \mathrm{X} 4$ isolates were composed by heterogeneous tropism quasispecies composition: 1 isolate (A32Sp) was represented by both $\mathrm{R} 5$ - and $\mathrm{X} 4$-using viruses 
Table 2

Phenotypic and genotypic characteristics of viral isolates.

\begin{tabular}{|c|c|c|c|c|c|c|c|c|c|c|}
\hline \multirow[t]{2}{*}{ Isolate } & \multirow[t]{2}{*}{ Phenotype $^{\mathrm{a}}$} & \multicolumn{5}{|c|}{$\begin{array}{l}\text { Phenotypic } \\
\text { characteristics }\end{array}$} & \multicolumn{4}{|l|}{$\begin{array}{l}\text { Genotypic } \\
\text { characteristics }\end{array}$} \\
\hline & & $\begin{array}{l}\text { Syncytia } \\
\text { inducing } \\
\text { ability }^{\mathrm{b}}\end{array}$ & $\begin{array}{l}\text { P24 level in } \\
\text { U87MG } \\
\mathrm{CD}^{+} / \mathrm{CCR} 5^{+} \\
(\mathrm{pg} / \mathrm{ml})^{\mathrm{c}}\end{array}$ & $\begin{array}{l}\text { P24 level in } \\
\text { U87MG } \\
\text { CD } 4^{+} / \mathrm{CXCR} 4^{+} \\
(\mathrm{pg} / \mathrm{ml})^{\mathrm{c}}\end{array}$ & Net charge ${ }^{d}$ & $\begin{array}{l}\text { Prediction } \\
\text { by G2Pe }\end{array}$ & $\begin{array}{l}\text { G2P false } \\
\text { positive rate }\end{array}$ & $\begin{array}{l}\text { Prediction } \\
\text { by } \text { PSSM }^{\mathrm{f}}\end{array}$ & $\begin{array}{l}\text { PSSM } \\
\text { score }\end{array}$ & $\begin{array}{l}\text { Glycosylation } \\
\text { Sites }^{g}\end{array}$ \\
\hline A48Sp & R5 & NSI & $>200$ & - & 3.09 & R5 & 42.6 & R5 & -12.909 & + \\
\hline RS & R5 & NSI & 34.2 & - & 5.00 & R5 & 44.2 & R5 & -10.675 & + \\
\hline MAVu & R5 & NSI & 36.6 & - & 4.09 & R5 & 44.2 & R5 & -12.151 & + \\
\hline FVSp & R5 & NSI & 40.2 & - & 3.91 & R5 & 39.6 & R5 & -8.486 & + \\
\hline BN12 & R5 & - & 25.1 & - & 3.09 & R5 & 45.1 & R5 & -9.302 & + \\
\hline CESp & R5 & NSI & $>200$ & - & 4.00 & R5 & 75.6 & $\mathrm{R} 5$ & -10.8725 & + \\
\hline $\mathrm{CFVu}$ & R5 & NSI & 44.2 & - & 3.50 & R5 & 78.8 & R5 & -10.624 & + \\
\hline CM1 & R5 & NSI & $>200$ & - & \multicolumn{6}{|c|}{ Sequence not available } \\
\hline DAGVu & R5 & NSI & 81.5 & - & 4.00 & $\mathrm{R} 5$ & 96.7 & R5 & -10.225 & + \\
\hline DC & R5 & - & $>200$ & - & 3.09 & R5 & 97.7 & R5 & -10.697 & + \\
\hline $\mathrm{FCVu}$ & R5 & NSI & 23 & - & 4.59 & R5 & 16.6 & R5 & -6.71 & + \\
\hline A75Sp & R5 & NSI & $>200$ & - & 4.09 & $\mathrm{X} 4$ & 4.2 & R5 & -10.58 & + \\
\hline FOTVu & R5 & NSI & 124 & - & 5.00 & R5 & 10.6 & R5 & -8.247 & + \\
\hline GCSp & R5 & NSI & $>200$ & - & 4.00 & R5 & 30.1 & R5 & -11.784 & + \\
\hline GRSp & R5 & NSI & $>200$ & - & 3.09 & R5 & 18.3 & R5 & -10.286 & + \\
\hline A245Sp & R5 & NSI & $>200$ & - & 4.00 & $\mathrm{X} 4$ & 2.1 & R5 & -11.055 & + \\
\hline LM & R5 & - & $>200$ & - & 4.09 & R5 & 35.6 & $\mathrm{R} 5$ & -11.755 & + \\
\hline LPSp & R5 & NSI & $>200$ & - & 4.09 & R5 & 33.7 & R5 & -12.05 & + \\
\hline CA4 & R5 & - & 39.4 & - & 3.00 & $\mathrm{X} 4$ & 1.7 & $\mathrm{X} 4$ & -5.652 & + \\
\hline MGVu & R5 & NSI & 30.8 & - & 4.50 & R5 & 53.8 & R5 & -9.346 & + \\
\hline $\mathrm{BC}$ & R5 & NSI & $>200$ & - & 2.91 & R5 & 63.1 & $\mathrm{X} 4$ & -4.991 & + \\
\hline MOI4 & R5 & NSI & $>200$ & - & \multicolumn{6}{|c|}{ Sequence not available } \\
\hline PASp & R5 & SI & $>200$ & - & 4.45 & R5 & 33.2 & X4 & -4.166 & + \\
\hline SA & R5 & NSI & $>200$ & - & 2.09 & R5 & 61.9 & R5 & -13.338 & + \\
\hline SASp & R5 & NSI & $>200$ & - & 3.50 & R5 & 38.1 & R5 & -12.195 & + \\
\hline SG & R5 & - & $>200$ & - & 4.91 & R5 & 28.8 & R5 & -8.278 & + \\
\hline SNVu & R5 & NSI & $>200$ & - & 4.00 & R5 & 14.4 & R5 & -11.608 & + \\
\hline $\mathrm{TL}$ & R5 & - & $>200$ & - & 4.41 & $\mathrm{X} 4$ & 2.8 & $\mathrm{X} 4$ & -3.829 & + \\
\hline TM & R5 & NSI & $>200$ & - & 2.64 & R5 & 49 & R5 & -14.106 & + \\
\hline TS3 & R5 & - & $>200$ & - & 3.09 & R5 & 18.9 & R5 & -11.498 & + \\
\hline $18 \mathrm{MM}$ & R5 & NSI & $>200$ & - & \multicolumn{6}{|c|}{ Sequence not available } \\
\hline A32Sp & $\mathrm{R}^{+} / \mathrm{X} 4$ & SI & $>20,000$ & 1358 & 6.00 & $\mathrm{X} 4$ & 1.1 & $\mathrm{X} 4$ & -4.385 & + \\
\hline $\mathrm{ACVu}$ & $\mathrm{R}^{+} / \mathrm{X} 4$ & SI & $>20,000$ & 119.8 & 3.00 & R5 & 47.8 & R5 & -13.61 & + \\
\hline $\mathrm{AMVu}$ & $\mathrm{R}^{+} / \mathrm{X} 4$ & NSI & $>20,000$ & 105.9 & 3.00 & R5 & 53.5 & R5 & -8.541 & + \\
\hline $\mathrm{CLVu}$ & $\mathrm{R}^{+} / \mathrm{X} 4$ & SI & $>20,000$ & 47.2 & 4.09 & R5 & 44.5 & R5 & -11.992 & + \\
\hline CRSp & $\mathrm{R}^{+} / \mathrm{X} 4$ & NSI & $>20,000$ & 1020 & 4.18 & R5 & 16.9 & R5 & -10.989 & + \\
\hline DVAVu & $\mathrm{R}^{+} / \mathrm{X} 4$ & SI & $>20,000$ & 45.9 & 1.09 & R5 & 95.2 & R5 & -12.677 & + \\
\hline MMSp & $\mathrm{R}^{+} / \mathrm{X} 4$ & NSI & 15,270 & 23.0 & 3.50 & R5 & 38.3 & R5 & -7.551 & + \\
\hline ND & $\mathrm{R}^{+} / \mathrm{X} 4$ & NSI & $>20,000$ & 200 & 2.91 & R5 & 46 & R5 & -11.682 & + \\
\hline $\mathrm{PLVu}$ & $\mathrm{R}^{+} / \mathrm{X} 4$ & NSI & $>20,000$ & 43.5 & 3.00 & R5 & 53.5 & R5 & -11.072 & + \\
\hline $\mathrm{RSVu}$ & $\mathrm{R}^{+} / \mathrm{X} 4$ & NSI & $>20,000$ & 19.7 & 3.00 & R5 & 27.2 & R5 & -10.117 & + \\
\hline VASp & $\mathrm{R}^{+} / \mathrm{X} 4$ & NSI & 5606 & 31.4 & 4.09 & R5 & 48 & R5 & -11.515 & + \\
\hline $\mathrm{PM}$ & $\mathrm{R}^{+} / \mathrm{X} 4$ & NSI & $>20,000$ & 25.1 & \multicolumn{6}{|c|}{ Sequence not available } \\
\hline A185Sp & $\mathrm{R} 5 / \mathrm{X} 4$ & SI & 76.6 & 120.5 & 6.00 & $\mathrm{X} 4$ & 0.2 & $\mathrm{X} 4$ & 2.283 & - \\
\hline $\mathrm{BMVu}$ & $\mathrm{R} 5 / \mathrm{X} 4$ & NSI & $>20,000$ & $>20,000$ & \multicolumn{6}{|c|}{ Sequence not available } \\
\hline FMVu & $\mathrm{R} 5 / \mathrm{X} 4$ & NSI & 18.5 & 18.0 & 4.00 & R5 & 12.1 & R5 & -9.144 & + \\
\hline $\mathrm{PA}$ & $\mathrm{R} 5 / \mathrm{X} 4$ & SI & 800 & 620 & 7.00 & $\mathrm{X} 4$ & 0.4 & $\mathrm{X} 4$ & -4.159 & + \\
\hline SFVu & $\mathrm{R} 5 / \mathrm{X} 4$ & NSI & 13.1 & 13.7 & 3.59 & $\mathrm{X} 4$ & 5 & R5 & -10.816 & + \\
\hline SPVu & $\mathrm{R} 5 / \mathrm{X} 4$ & SI & $>20,000$ & $>20,000$ & 4.50 & $\mathrm{X} 4$ & 1.7 & $\mathrm{X} 4$ & -0.3915 & + \\
\hline VCSP & $\mathrm{R} 5 / \mathrm{X} 4$ & NSI & 25.4 & 21.3 & 4.10 & R5 & 15.8 & R5 & -9.113 & + \\
\hline VRSp & $\mathrm{R} 5 / \mathrm{X} 4$ & SI & 40.6 & 39.8 & 6.09 & $\mathrm{X} 4$ & 0.2 & $\mathrm{X} 4$ & 2.973 & - \\
\hline A126Sp & $\mathrm{R} 5 / \mathrm{X} 4^{+}$ & SI & 27.5 & 1792 & 4.91 & $\mathrm{X} 4$ & 1.1 & $\mathrm{X} 4$ & -1.209 & + \\
\hline $\mathrm{BCSp}$ & $\mathrm{R} 5 / \mathrm{X} 4^{+}$ & SI & 94.1 & 1999 & 5.91 & $\mathrm{X} 4$ & 1.8 & $\mathrm{X} 4$ & -5.341 & + \\
\hline DPMVu & $\mathrm{X} 4$ & SI & - & $>200$ & 8.09 & $\mathrm{X} 4$ & 0.1 & $\mathrm{X} 4$ & 2.613 & - \\
\hline \multicolumn{11}{|c|}{ Control strains } \\
\hline $\mathrm{BaL}$ & R5 & - & $>200$ & - & 4.00 & R5 & 24.7 & R5 & -12.347 & + \\
\hline IIIB & $\mathrm{X} 4$ & - & - & $>200$ & 9.00 & $\mathrm{X} 4$ & 0.0 & $\mathrm{X} 4$ & 3.706 & + \\
\hline
\end{tabular}

a HIV-1 tropism was assessed through multiple cycles of replication test in U87MG-CD4 ${ }^{+} / \mathrm{CCR}^{+}$and $^{\text {U87MG-CD4 }}{ }^{+} / \mathrm{CXCR}^{+}$cells $^{-}$

b Syncytia inducing ability was determined through culture of viral stock supernatant containing 100 TCID 50 in MT-2 cells. Syncytia formation was defined as at least 10 multinucleated giant cells in five high-power fields after 4-weeks culture.

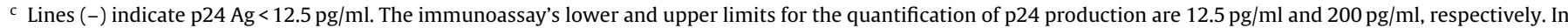
selected experiments, samples have been diluted and p24 further quantified up to $20,000 \mathrm{pg} / \mathrm{ml}$.

d V3 net charge was calculated through Innovagen's Peptide property calculator (http://www.innovagen.se/custom-peptide-synthesis/peptide-propertycalculator/peptide-property-calculator.asp).

e Geno2pheno (G2P) prediction algorithm is available at http://coreceptor.bioinf.mpi-inf.mpg.de/. False positive prediction rate limit was fixed at 10\%.

f PSSM prediction algorithm is available at http://fortinbras.us/cgi-bin/fssm/fssm.pl\#avg.

g N-glycosylation was predicted using the glycosite tool (http://www.hiv.lanl.gov/content/sequence/GLYCOSITE/glycosite.html). 
Table 3

V3 sequences alignment.

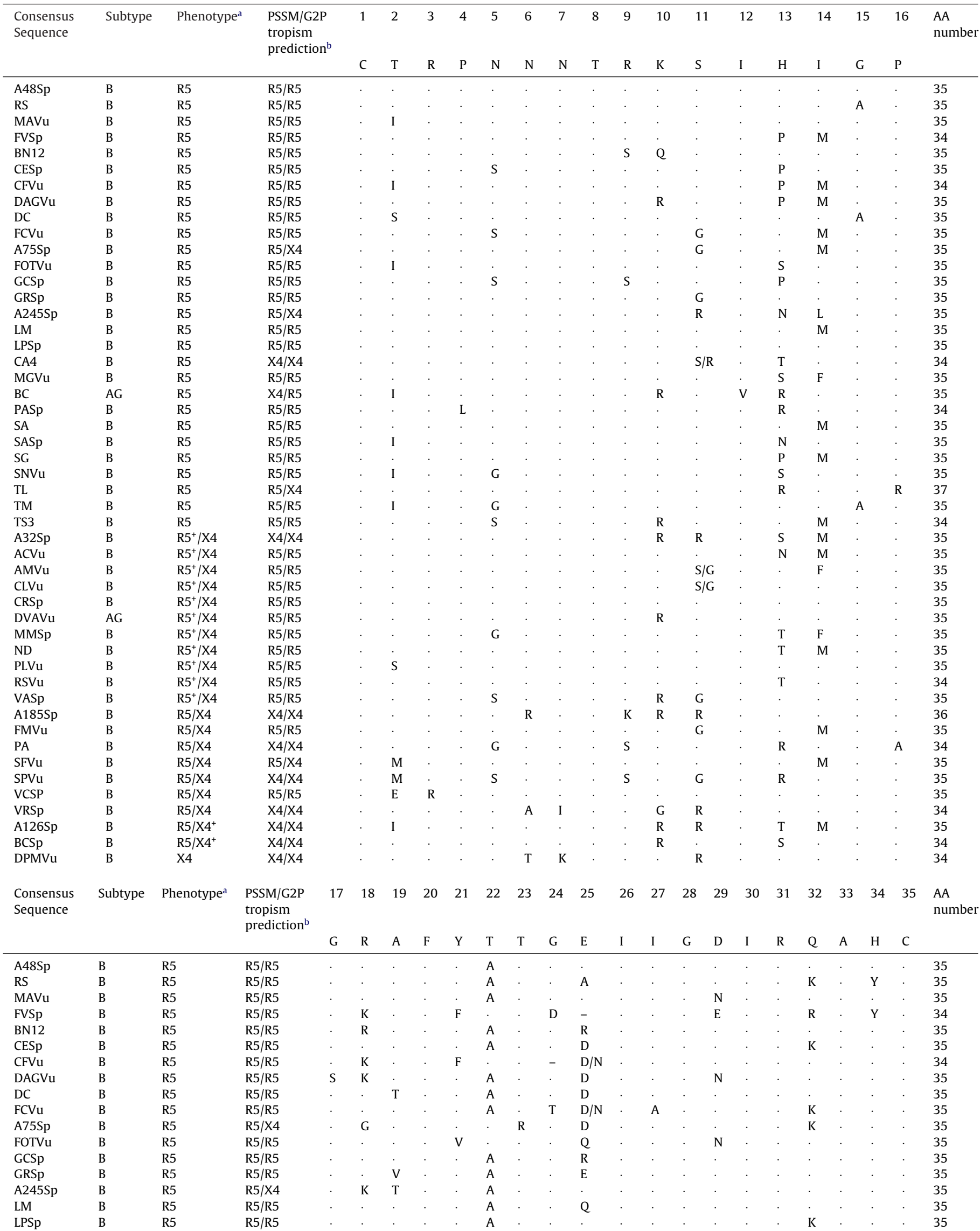


Table 3

(Continued)

\begin{tabular}{|c|c|c|c|c|c|c|c|c|c|c|c|c|c|c|c|c|c|c|c|c|c|c|c|}
\hline $\begin{array}{l}\text { Consensus } \\
\text { Sequence }\end{array}$ & Subtype & Phenotype $^{\mathrm{a}}$ & $\begin{array}{l}\text { PSSM/G2P } \\
\text { tropism } \\
\text { prediction }^{\mathrm{b}}\end{array}$ & 17 & 18 & 19 & 20 & 21 & 22 & 23 & 24 & 25 & 26 & 27 & 28 & 29 & 30 & 31 & 32 & 33 & 34 & 35 & $\begin{array}{l}\text { AA } \\
\text { number }\end{array}$ \\
\hline CA4 & B & R5 & $\mathrm{X} 4 / \mathrm{X} 4$ & . & $\mathrm{K}$ & $\mathrm{V}$ & . & . & $A$ & . &. & $\mathrm{D}$ & . & . & . & . &. & . &. & . & . & . & 34 \\
\hline MGVu & B & R5 & R5/R5 & . & $\mathrm{Q}$ & . & . & . & . & . & . & $\mathrm{D} / \mathrm{E}$ & . & . & . & . & . & . & $\mathrm{K}$ & . & . & . & 35 \\
\hline $\mathrm{BC}$ & AG & R5 & X4/R5 & . & $\mathrm{Q}$ & $\mathrm{T}$ & . & . & A & . & . & D & . & . & . & . & . & . & $\mathrm{K}$ & . & $\mathrm{Y}$ & . & 35 \\
\hline PASp & B & R5 & R5/R5 & . & $\mathrm{S}$ & $\mathrm{T}$ & . & . & . & $S$ & - & $\mathrm{L} / \mathrm{N}$ & . & . & . & . & . & . & . & . & $\mathrm{Y}$ & . & 34 \\
\hline SA & B & R5 & R5/R5 & . & G & . & . & . & A & . & . & D & . & . & . & . & . & . & . & . & . & . & 35 \\
\hline SASp & B & R5 & R5/R5 & . & . & . & . & . & A & . & . & D & . & . & . & . & . & . & $\mathrm{R}$ & . & . & . & 35 \\
\hline SG & B & R5 & R5/R5 & . & . & . & . & . & . & . & . & $\mathrm{Q}$ & . & . & . & . & . & . & $\mathrm{K}$ & . & $\mathrm{Y}$ & . & 35 \\
\hline SNVu & B & R5 & R5/R5 & . & . & . & . & . & A & . & . & $\mathrm{G}$ & . & . & . & . & . & . & . & . & . & . & 35 \\
\hline $\mathrm{TL}$ & B & R5 & $\mathrm{R} 5 / \mathrm{X} 4$ & . & . & . & . & . & A & $\mathrm{P}$ & . & . & . & . & . & . & . & . & $\mathrm{K}$ & . & $\mathrm{Y}$ & . & 37 \\
\hline TM & B & R5 & R5/R5 & . & . & . & . & . & A & . & . & $\mathrm{D}$ & . & . & . & . & . & . & . & . & . & . & 35 \\
\hline TS3 & B & R5 & R5/R5 & . & $\mathrm{K}$ & . & $\mathrm{Y}$ & . & . & . & $\mathrm{D}$ & - & . & . & . & . & . & . & . & . & . & . & 34 \\
\hline A32Sp & B & $\mathrm{R}^{+} / \mathrm{X} 4$ & $\mathrm{X} 4 / \mathrm{X} 4$ & . & . & . & $\mathrm{Y}$ & V & . & . & . & $\mathrm{Q}$ & . & . & . & $\mathrm{N}$ & . & . & . & . & . & . & 35 \\
\hline $\mathrm{ACVu}$ & B & $\mathrm{R}^{+} / \mathrm{X} 4$ & R5/R5 & . & . & . & . & . & A & . & . & . & V & . & . & . & . & . & . & . & . & . & 35 \\
\hline $\mathrm{AMVu}$ & $\mathrm{B}$ & $\mathrm{R}^{+} / \mathrm{X} 4$ & R5/R5 & . & $\mathrm{Q}$ & . & w & . & . & . & . & $\mathrm{Q}$ & . & . & . & . & . & . & . & . & $\mathrm{Y}$ & . & 35 \\
\hline CLVu & B & $\mathrm{R}^{+} / \mathrm{X} 4$ & R5/R5 & . & . & . & . & . & A & . & . & . & . & . & . & $\mathrm{N}$ & . & . & . & . & . & . & 35 \\
\hline CRSp & $\mathrm{B}$ & $\mathrm{R}^{+} / \mathrm{X} 4$ & R5/R5 & . & . & . & . & $\mathrm{H}$ & A & . & . & A & . & . & . & . & . & . & . & . & . & . & 35 \\
\hline DVAVu & AG & $\mathrm{R}^{+} / \mathrm{X} 4$ & R5/R5 & . & $\mathrm{Q}$ & . & . & . & A & . & . & $\mathrm{D}$ & . & . & . & . & . & . & . & . & . & . & 35 \\
\hline MMSp & B & $\mathrm{R}^{+} / \mathrm{X} 4$ & R5/R5 & . & . & . & . & $\mathrm{F}$ & . & . & . & $\mathrm{D}$ & . & . & . & . & . & . & $\mathrm{N}$ & . & . & . & 35 \\
\hline ND & B & $\mathrm{R}^{+} / \mathrm{X} 4$ & R5/R5 & . & . & . & . & . & A & . & . & . & . & . & . & . & . & . & . & . & $\mathrm{Y}$ & . & 35 \\
\hline PLVu & $\mathrm{B}$ & $\mathrm{R}^{+} / \mathrm{X} 4$ & R5/R5 & . & $\mathrm{K}$ & . & . & . & A & . & . & . & . & . & . & . & . & . & . & . & $\mathrm{Y}$ & . & 35 \\
\hline $\mathrm{RSVu}$ & B & $\mathrm{R}^{+} / \mathrm{X} 4$ & R5/R5 & . & . & . & . & . & A & . & $\mathrm{D}$ & - & . & . & . & . & . & . & . & . & . & . & 34 \\
\hline VASp & B & $\mathrm{R}^{+} / \mathrm{X} 4$ & R5/R5 & . & . & . & . & . & A & . & . & A & . & $\mathrm{T}$ & . & . & . & . & . & . & . & . & 35 \\
\hline A185Sp & B & $\mathrm{R} 5 / \mathrm{X} 4$ & $\mathrm{X} 4 / \mathrm{X} 4$ & . & . & $\mathrm{S}$ & . & . & G & A & . & . & V & $\mathrm{T}$ & . & . & . & . & $\mathrm{R}$ & . & $\mathrm{Y}$ & . & 36 \\
\hline FMVu & B & $\mathrm{R} 5 / \mathrm{X} 4$ & R5/R5 & . & $\mathrm{K}$ & . & . & . & A & . & $\mathrm{T}$ & D & . & . & . & . & . & . & $\mathrm{K}$ & . & $\mathrm{Y}$ & . & 35 \\
\hline PA & B & $\mathrm{R} 5 / \mathrm{X} 4$ & $\mathrm{X} 4 / \mathrm{X} 4$ & $\mathrm{R}$ & $\mathrm{K}$ & - & . & . & A & $\mathrm{R}$ & $\mathrm{E}$ & $\mathrm{R}$ & . & . & . & . & $\mathrm{T}$ & . & $\mathrm{R}$ & . & . & . & 34 \\
\hline SFVu & B & $\mathrm{R} 5 / \mathrm{X} 4$ & $\mathrm{R} 5 / \mathrm{X} 4$ & . & . & . & . & . & . & . & . & D & . & . & . & $\mathrm{N}$ & . & . & . & . & . & . & 35 \\
\hline SPVu & B & $\mathrm{R} 5 / \mathrm{X} 4$ & $\mathrm{X} 4 / \mathrm{X} 4$ & . & . & . & V & . & A & A & $\mathrm{D} / \mathrm{E}$ & $\mathrm{K}$ & . & . & . & . & . & . & . & . & . & . & 35 \\
\hline VCSP & B & $\mathrm{R} 5 / \mathrm{X} 4$ & R5/R5 & . & . & . & . & . & . & . & . & A & . & . & . & . & . & . & $\mathrm{K}$ & . & . & . & 35 \\
\hline VRSp & B & $\mathrm{R} 5 / \mathrm{X} 4$ & $\mathrm{X} 4 / \mathrm{X} 4$ & . & . & . & . & $\mathrm{H}$ & A & . & - & $\mathrm{K}$ & $\mathrm{T}$ & . & K & . & . & . & . & . & $\mathrm{Y}$ & . & 34 \\
\hline A126Sp & B & $\mathrm{R} 5 / \mathrm{X} 4^{+}$ & $\mathrm{X} 4 / \mathrm{X} 4$ & . & . & V & $\mathrm{L}$ & . & . & . & . & . & . & . & . & . & . & . & K & . & $\mathrm{Y}$ & . & 35 \\
\hline BCSp & B & $\mathrm{R} 5 / \mathrm{X} 4^{+}$ & $\mathrm{X} 4 / \mathrm{X} 4$ & . & . & . & . & - & . & . & $\mathrm{R}$ & $\mathrm{Q}$ & . & . & . & . & . & . & $\mathrm{K}$ & . & $\mathrm{Y}$ & . & 34 \\
\hline DPMVu & B & $\mathrm{X} 4$ & $\mathrm{X} 4 / \mathrm{X} 4$ & . & . & 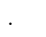 & . & . & . & . & $\mathrm{K}$ & - & $\mathrm{T}$ & V & $\mathrm{R}$ & . & . & . & . & . & . & . & 34 \\
\hline
\end{tabular}

a HIV-1 tropism was assessed through multiple cycles of replication test in U87MG-CD4 ${ }^{+} / \mathrm{CCR}^{+}$and U87MG-CD4 ${ }^{+} / \mathrm{CXCR} 4^{+}$cells.

b Geno2pheno (G2P) prediction algorithm is available at http://coreceptor.bioinf.mpi-inf.mpg.de/. False positive prediction rate limit was fixed at 10\%. PSSM prediction algorithm is available at http://fortinbras.us/cgi-bin/fssm/fssm.pl\#avg.

(724 R5-sequences, $17.5 \%$ prevalence; and 3584 X4-sequences, $82.5 \%$ prevalence confirming the $\mathrm{X} 4$-prediction obtained by the standard-genotype for such sample, see Table 2), while the other isolate (RSV) showed the majority of species as R5 (10,421 R5sequences, $99.6 \%$ prevalence) and few X4-using minority species (94 X4-sequences, 0.4\% prevalence). Only R5-using species were found in the phenotypically R5/X4 isolate (SFVu) analyzed (PSSM score range: $-11.2 ;-9.15)$.

In parallel, only X4-using species were observed in the pure$\mathrm{X} 4$ isolate (median[IQR] PSSM-score $=2.6[1.9 ; 3.4]$ ). Both R5/X4+ isolates were composed by only (A126Sp) or mostly (BCSp, 96.3\%) of $\mathrm{X} 4$-using viruses (median[IQR] PSSM-score $=-2.0[-2.3 ;-1.6]$, and

Table 4

Mutations in gp120 and gp41 significantly associated with tropism and/or syncytium inducing ability.

\begin{tabular}{|c|c|c|c|c|c|c|c|c|c|}
\hline Domain & & Association & $\begin{array}{l}\text { Non-syncytium } \\
\text { inducing } \\
(N=34)\end{array}$ & $\begin{array}{l}\text { Syncytium } \\
\text { inducing } \\
(N=12)\end{array}$ & $\begin{array}{l}\text { Pure R5 } \\
\text { phenotype } \\
(N=24)\end{array}$ & $\begin{array}{l}\text { Dual/Mixed } \\
\text { (D/M) phenotype } \\
(N=20)\end{array}$ & $\begin{array}{l}\text { Pure X4 } \\
\text { phenotype } \\
(N=1)\end{array}$ & $\begin{array}{l}P \text {-value NSI } \\
\text { vs. SI }\end{array}$ & $\begin{array}{l}P \text {-value R5 } \\
\text { vs. } \mathrm{D} / \mathrm{M}^{\mathrm{b}}\end{array}$ \\
\hline \multicolumn{10}{|c|}{ gp120 mutations } \\
\hline $\mathrm{K} 5 \mathrm{~N}$ & $\mathrm{C} 1$ & R5 & $6(17.6)$ & $1(8.3)$ & $9(37.5)$ & $1(5.0)$ & $0(0)$ & NS & 0.012 \\
\hline Y33H & $\mathrm{C} 1$ & $\mathrm{D} / \mathrm{M}-\mathrm{SI}$ & $1(2.9)$ & $3(25.0)$ & $0(0)$ & $4(20.0)$ & $0(0)$ & 0.049 & 0.036 \\
\hline T206K & $\mathrm{C} 2^{\mathrm{c}}$ & SI & $0(0)$ & $3(25.0)$ & $0(0)$ & $3(15.0)$ & $0(0)$ & 0.024 & NS \\
\hline T206S & $\mathrm{C} 2^{\mathrm{c}}$ & SI & $0(0)$ & $3(25.0)$ & $0(0)$ & $3(15.0)$ & $0(0)$ & 0.024 & NS \\
\hline R304G & $\mathrm{C}^{\mathrm{d}}$ & SI & $4(20.0)$ & $7(70.0)$ & $4(16.7)$ & $8(40.0)$ & $0(0)$ & 0.015 & NS \\
\hline $\mathrm{I} 339 \mathrm{~V}$ & $\mathrm{C}^{\mathrm{d}}$ & R5 & $1(5.0)$ & $1(10.0)$ & $5(31.2)$ & $0(0)$ & $0(0)$ & NS & 0.007 \\
\hline \multicolumn{10}{|c|}{ gp41 mutation ${ }^{\mathrm{e}}$} \\
\hline M7L & & NSI & $15(65.2)$ & $2(22.2)$ & $9(50.0)$ & $9(50.0)$ & - & 0.049 & NS \\
\hline N140I & & SI & $1(4.3)$ & $5(55.6)$ & $3(16.7)$ & $4(22.2)$ & - & 0.003 & NS \\
\hline L244I & & $\mathrm{D} / \mathrm{M}-\mathrm{SI}$ & $8(34.8)$ & $8(88.9)$ & $5(27.8)$ & $13(72.2)$ & - & 0.016 & 0.018 \\
\hline
\end{tabular}

a Mutations with a significantly different prevalence among non-syncytium inducing (NSI) and syncytium inducing (SI) viral strains. $P$-values were calculated through Fisher exact test and were considered as significative when $<0.05$ after Benjamin-Hockberg correction.

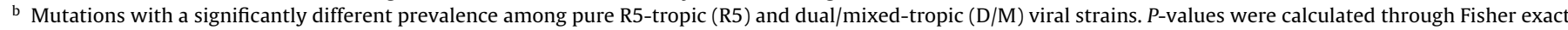
test and were considered as significative when $<0.05$ after Benjamin-Hockberg correction.

c The prevalence of mutations was calculated on 20 NSI and 10 SI, 16 R5-tropic and 17 dual/mixed-tropic isolates

d The prevalence of mutations was calculated on 27 NSI and 12 SI strains.

e The prevalence of mutations was calculated on 23 NSI and 9 SI strains, 18 R5-tropic and 18 dual/mixed-tropic isolates. GP41 sequence of X4-tropic isolate was not available. 


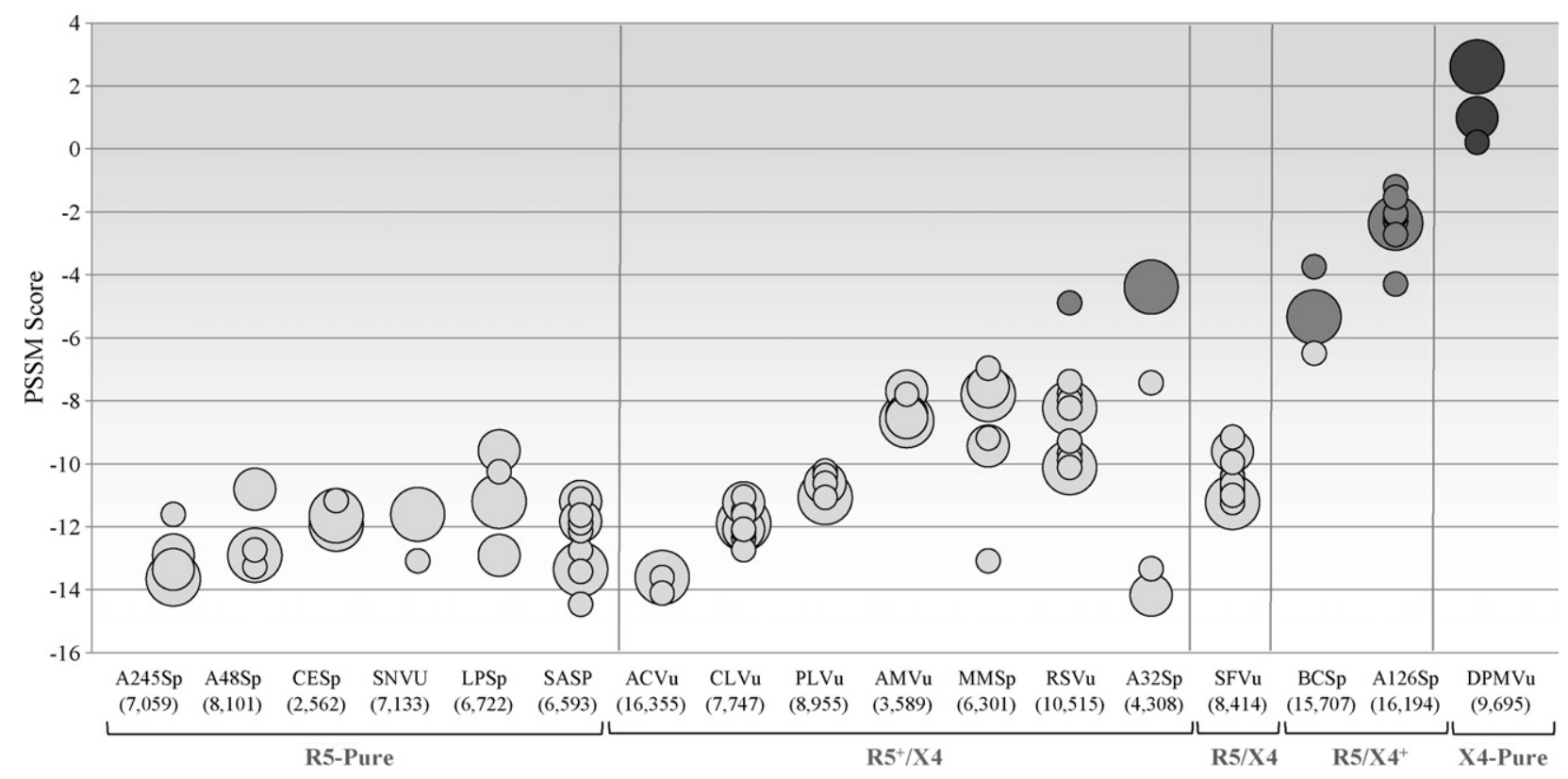

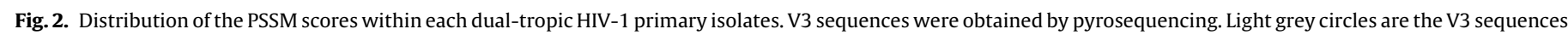

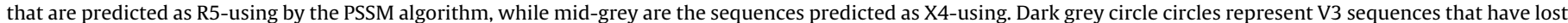

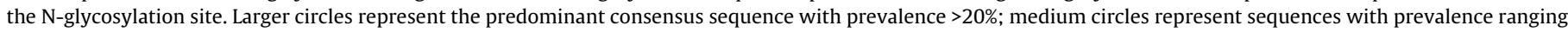
from 5 to $20 \%$, while smaller circles represent sequences with low prevalence $(<5 \%)$. The total number of sequences obtained for each sample is also shown.

$-4.3[-5.1 ;-3.9]$, respectively), confirming the standard-genotype results (Fig. 2).

Thus, UDPS analyses also show similar genotypic characteristics between pure $\mathrm{R} 5-$ and $\mathrm{R}^{+} / \mathrm{X} 4$-isolates.

\subsection{Evaluation of in vitro maraviroc selection of X4-tropic viruses}

A further step of our study was to evaluate the in vitro emergence of X4-tropic strains from $\mathrm{R} 5, \mathrm{R}^{+} / \mathrm{X} 4$ and $\mathrm{R} 5 / \mathrm{X} 4^{+}$isolates as a potential consequence of the positive selective pressure imposed by maraviroc treatment. For this purpose, we selected $7 \mathrm{R}^{+} / \mathrm{X} 4,1$ $\mathrm{R} 5 / \mathrm{X}^{+}$and 2 pure-R5 isolates (all analyzed also by V3 ultra-deep pyrosequencing) to infect PBMCs. $\mathrm{HIV}_{\mathrm{BaL}}, \mathrm{HIV}_{\mathrm{IIIB}}$ and the pure-X4 isolate were used as controls. In the absence of drug-pressure, viral replication was detectable up to 35 days in all viral isolates. Viral replication was also observed up to the seventh co-culture ( 2 months) in 6 out of 10 viral-isolates (Table 5). As expected, AZT $(1 \mu \mathrm{M})$ fully inhibited ( $>99 \%)$ the replication of all tested viruses. Also maraviroc (at both $40 \mathrm{nM}$ and $200 \mathrm{nM}$ ) fully inhibited not only the replication of the 2 pure- $\mathrm{R} 5$ isolates and the pure-R5 laboratorystrain $\mathrm{HIV}_{\mathrm{BaL}}$, but also of all $\mathrm{R}^{+} / \mathrm{X} 4$-strains tested in this assay, independently if they were syncytium-inducing in MT2-cells or not. Thus, no emergence of X4-tropic variants was observed during in vitro maraviroc selection experiments on PBMCs, even in those isolates showing the presence of X4-using species by UDPS (RSVu, $0.4 \%$ $\mathrm{X} 4$, and $\mathrm{A} 32 \mathrm{Sp}, 82.5 \% \mathrm{X} 4$ ) and in the isolate (BCSp) with a preferential use for CXCR4 coreceptor (Table 5). By contrast, the replication of the pure-X4 laboratory-strain $\mathrm{HIV}_{\mathrm{IIIB}}$, and of the pure-X4 isolate, was not at all inhibited by maraviroc at any concentration tested.

\section{Discussion}

This study highlights the existence of different types of $\mathrm{D} / \mathrm{M}$-tropic viruses, with a preferential co-receptor usage in a considerable rate of clinical isolates, which is largely underestimated by the tropism determination assays currently used in clinical practice. Using primary HIV-1 isolates in multiple cycles phenotypic assay (and not using env pseudoviruses in a single-cycle assay, as generally described in this type of studies), we showed that $\mathrm{R}^{+} / \mathrm{X} 4$ viruses (with a preference for CCR5) are similar both genotypically and phenotypically to pure-R5 viruses, while $\mathrm{R} 5 / \mathrm{X} 4^{+}$viruses (with a preference for CXCR4) are similar (at least genetically) to the pure$\mathrm{X} 4$ virus. This finding was also supported by UDPS, showing the presence of a swarm of genetically distinct species with extensive preference for CCR5-coreceptor in nearly all strains otherwise generally defined as D/M tropic. Similarly, in D/M tropic isolates with preference for CXCR4, we observed extensive prevalence of X4using species. This fully supports the concept that the dual-tropic viruses represent a quite heterogeneous population, in which dual$\mathrm{R} 5$ mostly behave as R5-viruses, and dual-X4 are closely related to $\mathrm{X} 4$-viruses.

Moreover, under maraviroc pressure, there was a full inhibition of viral replication and no selection (up to 2 months of culture) of X4-viruses in $\mathrm{R}^{+} / \mathrm{X} 4$-tropic isolates, thus confirming that such dual-tropic viruses with R5 preference mostly behave as pure R5. This finding can have important clinical implications for an optimized use of CCR5 antagonists in clinical practice.

In this regard, we found that maraviroc at concentrations of $200 \mathrm{nM}$ and $40 \mathrm{nM}$ (the latter close to the minimal concentration [Cmin] achieved in the plasma of patients treated with common maraviroc dosage of $300 \mathrm{mg}$ ) inhibited in vitro the replication of $\mathrm{R}^{+} / \mathrm{X} 4$-isolates, including those with $\mathrm{X} 4$-tropic viruses present as minor (RSVu) or even major species (A32Sp). Although this result requires further investigation, it is consistent with recent studies (Fransen et al., 2008; Symons et al., 2011; Toma et al., 2010). In particular, Toma et al. (2010), in a single-cycle replication assay, showed that $\mathrm{R} 5^{+} / \mathrm{X} 4$ viruses were efficiently inhibited by a Merck CCR5-antagonist, but not by AMD3100 (a CXCR4antagonist), whereas $\mathrm{R} 5 / \mathrm{X} 4^{+}$viruses were efficiently inhibited by the CXCR4-antagonist AMD-3100, but not by the CCR5-antagonist. Conversely, dual-tropic viruses that use the co-receptor with the same efficiency were not or only partially inhibited, by either CCR5or the CXCR4-antagonist alone (Toma et al., 2010). It should be noted that this study has been performed with pseudotypic viruses (not clinical isolates), exposed to co-receptor antagonists not used in clinical practice. For this reason, the confirmation of these results 
Table 5

No viral breakthrough in co-cultures of PBMC infected with dual-tropic isolates and treated with maraviroc.

\begin{tabular}{|c|c|c|c|c|}
\hline \multirow[t]{2}{*}{ Isolate } & \multirow[t]{2}{*}{ Phenotype $^{\mathrm{a}}$} & \multirow[t]{2}{*}{ Treatments } & IV co-culture ${ }^{\mathrm{b}}$ & VII co-culture ${ }^{\mathrm{b}}$ \\
\hline & & & \multicolumn{2}{|c|}{ Replicating virus $^{\mathrm{c}}$} \\
\hline \multirow{5}{*}{ CESp } & \multirow{5}{*}{ R5 } & None & +++ & +++ \\
\hline & & Maraviroc $200 \mathrm{nM}$ & - & - \\
\hline & & Maraviroc $40 \mathrm{nM}$ & - & - \\
\hline & & AZT $1 \mu \mathrm{M}$ & - & - \\
\hline & & None & +++ & +++ \\
\hline \multirow{3}{*}{ SASp } & \multirow{3}{*}{$\mathrm{R} 5$} & Maraviroc $200 \mathrm{nM}$ & - & - \\
\hline & & Maraviroc $40 \mathrm{nM}$ & - & - \\
\hline & & AZT $1 \mu \mathrm{M}$ & - & - \\
\hline \multirow{5}{*}{ A32Sp } & \multirow{4}{*}{$\mathrm{R}^{+} / \mathrm{X} 4$} & None & +++ & +++ \\
\hline & & Maraviroc $200 \mathrm{nM}$ & - & - \\
\hline & & Maraviroc $40 \mathrm{nM}$ & - & - \\
\hline & & AZT $1 \mu \mathrm{M}$ & - & - \\
\hline & \multirow{4}{*}{$\mathrm{R}^{+} / \mathrm{X} 4$} & None & +++ & ++ \\
\hline \multirow{3}{*}{ ACV } & & Maraviroc $200 \mathrm{nM}$ & - & - \\
\hline & & Maraviroc $40 \mathrm{nM}$ & - & - \\
\hline & & AZT $1 \mu \mathrm{M}$ & - & - \\
\hline \multirow{4}{*}{ AMV } & \multirow{4}{*}{$\mathrm{R}^{+} / \mathrm{X} 4$} & None & +++ & +++ \\
\hline & & Maraviroc $200 \mathrm{nM}$ & - & - \\
\hline & & Maraviroc $40 \mathrm{nM}$ & - & - \\
\hline & & AZT $1 \mu \mathrm{M}$ & - & - \\
\hline \multirow{4}{*}{$\mathrm{CLVu}$} & \multirow{4}{*}{$\mathrm{R}^{+} / \mathrm{X} 4$} & None & + & - \\
\hline & & Maraviroc $200 \mathrm{nM}$ & - & NA \\
\hline & & Maraviroc $40 \mathrm{nM}$ & - & NA \\
\hline & & AZT $1 \mu \mathrm{M}$ & - & NA \\
\hline \multirow{3}{*}{ MMSp } & \multirow{3}{*}{$\mathrm{R}^{+} / \mathrm{X} 4$} & None & ++ & ++ \\
\hline & & Maraviroc $200 \mathrm{nM}$ & - & - \\
\hline & & AZT $1 \mu \mathrm{M}$ & - & - \\
\hline \multirow{4}{*}{ PLVu } & \multirow{4}{*}{$\mathrm{R}^{+} / \mathrm{X} 4$} & None & ++ & - \\
\hline & & Maraviroc $200 \mathrm{nM}$ & - & NA \\
\hline & & Maraviroc $40 \mathrm{nM}$ & - & NA \\
\hline & & AZT $1 \mu \mathrm{M}$ & - & NA \\
\hline \multirow{5}{*}{$\mathrm{RSVu}$} & & None & ++ & - \\
\hline & & Maraviroc $200 \mathrm{nM}$ & - & NA \\
\hline & $\mathrm{R}^{+} / \mathrm{X} 4$ & Maraviroc $40 \mathrm{nM}$ & - & NA \\
\hline & & AZT $1 \mu \mathrm{M}$ & - & NA \\
\hline & & None & +++ & +++ \\
\hline & & Maraviroc $200 \mathrm{nM}$ & - & - \\
\hline BCSp & $\mathrm{R} 5 / \mathrm{X} 4^{+}$ & Maraviroc $40 \mathrm{nM}$ & - & - \\
\hline & & AZT $1 \mu \mathrm{M}$ & - & - \\
\hline Controls & & & & \\
\hline & & None & +++ & +++ \\
\hline $\mathrm{BaL}$ & R5 & Maraviroc $200 \mathrm{nM}$ & - & - \\
\hline & & AZT $1 \mu \mathrm{M}$ & - & - \\
\hline & & None & ++ & - \\
\hline & & Maraviroc $200 \mathrm{nM}$ & ++ & NA \\
\hline DPMV & $\mathrm{X} 4$ & Maraviroc $40 \mathrm{nM}$ & ++ & NA \\
\hline & & AZT $1 \mu \mathrm{M}$ & + & NA \\
\hline & & None & +++ & +++ \\
\hline IIIB & $\mathrm{X} 4$ & Maraviroc $200 \mathrm{Nm}$ & +++ & +++ \\
\hline & & AZT $1 \mu \mathrm{M}$ & - & - \\
\hline
\end{tabular}

NA: not applicable.

${ }^{a}$ HIV-1 tropism was assessed through multiple cycles of replication test in U87MG-CD $4^{+} / \mathrm{CCR}^{+}$and $\mathrm{U} 87 \mathrm{MG}-\mathrm{CD} 4^{+} / \mathrm{CXCR} 4^{+}$cells.

b PBMC infected with $12,000 \mathrm{pg} / \mathrm{ml}$ of each strain were co-cultivated with fresh PBMC in presence of maraviroc or AZT up to VII co-culture.

c Viral replication was assessed by p24 quantification in culture supernatants. +++, p24>3000 pg/ml; ++, p24=400-3000 pg/ml; +, p24<400 pg/ml; -, no p24 production.

achieved in our study using clinical isolates, stands as a relevant point in order to get closer to clinical situation. Similarly, another study has shown the ability of the CXCR4 antagonist AMD3100 to inhibit the replication of dual-tropic viruses that use more efficiently the CXCR4 co-receptor than the CCR5 (Fransen et al., 2008).

Moreover, our results are also consistent with the data from the A4001029-study, a Phase 2b clinical trial, where patients carrying non-R5 viruses were treated with maraviroc-containing regimen. This study has indeed shown the suppression of viremia below 50 copies $/ \mathrm{ml}$ in $27 \%$ of patients with $\mathrm{D} / \mathrm{M}$-tropic viruses at week 48 of a maraviroc-containing regimen (Saag et al., 2009). In particular, a marked decrease of viremia (close to that achieved in patients carrying $\mathrm{R} 5$ virus) at week- 12 was observed in patients with a rate of X4-tropic viruses $<10 \%$ (Swenson et al., 2009). Thus, all these findings suggest that CCR5-antagonists (especially when adminis- tered together with other active drugs) may represent a therapeutic option that deserves attention also in selected patients carrying a $\mathrm{D} / \mathrm{M}$-tropic virus. This further supports the concept of extending the use of CCR5-antagonists to a spectrum of patients potentially larger than only those infected with a full R5-virus. However, further clinical validation is required in order to confirm in vivo our hypothesis.

Finally, it should be noted that in the Merit Trial maraviroc arm, the enhanced sensitivity version of Trofile (ESTA) reclassified as dual/mixed 48/360 (13.3\%) of patients who had an R5 tropism result at screening with the original Trofile assay. Despite the exclusion of these patients from the reanalysis, virological success (HIV-1 RNA $<50$ copies $/ \mathrm{ml}$ ) to maraviroc-containing regimen was observed in $68.5 \%$ patients compared to $65.3 \%$ in the original analysis (Saag et al., 2008; Cooper et al., 2010). Thus, only a 3.2\% improvement in 
virological response to maraviroc was observed despite this reclassification. In addition, a further analysis shows that 21 out of 48 (45\%) patients reclassified as dual/mixed by ESTA, achieved virological success at 48 week of maraviroc treatment (Swenson et al., 2009).

The fact that we did not observe at the seventh co-culture (up to 2 months) of maraviroc treatment a viral rebound in viruses with minority X4-using species (prevalence $<0.5 \%$ of the entire viral population) can be explained by a recent study showing that virological-failure to maraviroc is related to the outgrowth of preexisting minority X4-using species only if present at a prevalence $>2 \%$ at the time of starting of maraviroc treatment (Swenson et al., 2010a,b). This is consistent with a previous study showing the lack of X4-species emergence in a R5 primary isolate after several passages in PBMCs using increasing concentration of the CCR5-specific small molecule inhibitor AD101 (Trkola et al., 2002). It is conceivable that these minority X4-tropic species, found at a very low prevalence, are characterized by a very low replication capacity that does not allow them to replicate and become the predominant species. One potential exception to this rule is the case of the quantitatively prevalent X4-tropic species found in the $\mathrm{R}^{+} / \mathrm{X} 4 \mathrm{~A} 32 \mathrm{Sp}$ isolate ( $82 \% \mathrm{X} 4$ of the viral-population), and in the $\mathrm{R} 5 / \mathrm{X} 4^{+} \mathrm{BCSp}$ isolate (96.5\% X4 of the viral population) also inhibited in vitro by maraviroc. An intriguing hypothesis regarding these two isolates is consistent with a recent study showing that specific antagonists of one among CCR5, CXCR4, and CCR2 receptors lead to functional cross-inhibition of the others (even without a direct binding) (Sohy et al., 2009). Under these circumstances, it is possible that maraviroc in some cases regulates CXCR4 ability to act as receptor for $\mathrm{X} 4$-virus strains, thus indirectly inhibiting their replication and outgrowth. There are evident clinical implications of this hypothesis, which require confirmation in other settings. Thus, overall results suggest that the drug-mediated inhibition of HIV-interaction with coreceptors is by far more complex than previously thought, and that the mechanisms underlying such inhibition still need to be in depth assessed.

Our detailed genotypic analysis showed that PSSM scores and geno2pheno FPRs were statistically associated with both CCR5usage and syncytium-inducing phenotype. Indeed, we found that the non-syncytium-inducing, pure- $\mathrm{R} 5$, and $\mathrm{R}^{+} / \mathrm{X} 4$ isolates were associated with the lowest PSSM scores, while the syncytiuminducing, pure- $\mathrm{X} 4, \mathrm{R} 5 / \mathrm{X} 4^{+}$and $\mathrm{R} 5 / \mathrm{X} 4$ isolates associated with the highest PSSM values. Similarly, higher FPRs were observed for the non-syncytium-inducing, pure-R5 and $\mathrm{R}^{+} / \mathrm{X} 4$ isolates, while lower FPRs were associated with the syncytium-inducing, pure-X4, $\mathrm{R} 5 / \mathrm{X}^{+}$, and $\mathrm{R} 5 / \mathrm{X} 4$ isolates.

In addition, analyzing the entire gp160 sequence in a subset of isolates, we found the existence of some specific genetic markers in gp120 and gp41 (outside the classical V3 region) correlating with different co-receptor usage, and also with syncytium inducing ability. This is consistent with previous studies showing the involvement of the V1, V2, and C4 domain in mechanisms underlying co-receptor usage (Huang et al., 2007; Kupfer et al., 2007; Thielen et al., 2010).

Overall, these results highlight that genotypic testing for tropism determination can provide important information regarding the viral potential to use the different co-receptors and cytopathic properties, supporting the role of genotypic tropism testing as a valid and accurate assay.

Even if this study is focusing on a large number of primary isolates, it has some potential limitations: the fact that these isolates were obtained from cell-associated HIV-provirus may have limited the number of quasispecies captured. Second, the methodology used to generate viral isolates (based on $\mathrm{CD}^{+}$-depleted PBMC co-culture) could have posed a selective pressure towards the use of a specific co-receptor. However, our results are sim- ilar to those obtained in other studies where viral tropism and quasispecies-variability within each subject were investigated at both plasmatic and cellular level (Rozera et al., 2009; Swenson et al., 2010a,b). Third, we assessed viral tropism by using a phenotypic assay based on multiple cycles of replication. Differently from single cycle replication assay, multiple cycle assay, even if it shows greater sensitivity, may result on the evolution of the viral population during the assay with consequent changes in viral tropism. Finally, by using the ultra-deep V3 sequencing for the evaluation of quasispecies composition of viral isolates, we are aware that this methodology requires further clinical validation in term of reproducibility of results.

\section{Conclusions}

Although our results require a clinical validation, they show that among primary HIV-1 isolates, dual-tropic viruses are mostly constituted by a swarm of species with different dual-mixed tropism potential, with a frequently predefined preference for CCR5, and whose replication is well- and long-term controlled by CCR5antagonists despite their potential ability to enter through CXCR4 co-receptor. Both population-based and ultra-deep sequencing can be used for an optimal prediction of viral-tropism. Taken together, these data suggest a far more important role of CCR5 (compared to CXCR4) in regulating the replication of HIV in CD4-lymphocytes, even under conditions of inhibitors-driven limitation of CCR5usage. For these reasons, the use of CCR5-antagonists in patients with $\mathrm{R}^{+} / \mathrm{X} 4$-tropic viruses can represent a therapeutic option that deserves further clinical investigation.

\section{Transparency declaration}

Drs. Stuyver, Vandenbroucke, Van Marck, Mostmans and Aerssens report being employees of Virco BVBA or Tibotec-Virco BVBA, Johnson \& Johnson companies, who are owners of the antiretroviral drugs darunavir and etravirine. The other authors declare no competing interests.

\section{Acknowledgements}

This work was financially supported by grants from the Italian National Institute of Health, the Ministry of University and Scientific Research, Current and Finalized Research of the Italian Ministry of Health, an unrestricted educational grant from Pfizer, and by the European Commission Framework 7 Programme (CHAIN, the Collaborative HIV and Anti-HIV Drug Resistance Network, Integrated Project no. 223131), and from European AIDS Treatment Network (NEAT, contract number LSHT/CT/2006/037570).

We thank Fabiola Di Santo, Fernanda Scopelliti, Michela Pollicita, Roberta Cammarota, Amalia Mastrofrancesco, Daniele Pizzi, Lavinia Fabeni, Francesca Stazi, Ada Bertoli, and Marco Montano for excellent technical assistance.

\section{References}

Andreoni, M., Parisi, S.G., Sarmati, L., Nicastri, E., Ercoli, L., Mancino, G., Sotgiu, G., Mannazzu, M., Trevenzoli, M., Tridente, G., Concia, E., Aceti, A., 2000. Cellular proviral HIV-DNA decline and viral isolation in naive subjects with $<5000$ copies/ml of HIV-RNA and $>500 \times 10(6) / 1$ CD4 cells treated with highly active antiretroviral therapy. AIDS 14, 23-29.

Aquaro, S., Guenci, T., Di, S.F., Francesconi, M., Calio, R., Perno, C.F., 2004. Potent antiviral activity of amprenavir in primary macrophages infected by human immunodeficiency virus. Antiviral Res. 61, 133-137.

Aquaro, S., Menten, P., Struyf, S., Proost, P., Van, D.J., De, C.E., Schols, D., 2001. The LD78beta isoform of MIP-1alpha is the most potent CC-chemokine in inhibiting CCR5-dependent human immunodeficiency virus type 1 replication in human macrophages. J. Virol. 75, 4402-4406.

Berger, E.A., 1998. HIV entry and tropism. When one receptor is not enough. Adv. Exp. Med. Biol. 452, 151-157. 
Brumme, Z.L., Goodrich, J., Mayer, H.B., Brumme, C.J., Henrick, B.M., Wynhoven, B., Asselin, J.J., Cheung, P.K., Hogg, R.S., Montaner, J.S., Harrigan, P.R., 2005. Molecular and clinical epidemiology of CXCR4-using HIV-1 in a large population of antiretroviral-naive individuals. J. Infect. Dis. 192, 466-474.

Church, J.D., Huang, W., Mwatha, A., Toma, J., Stawiski, E., Donnell, D., Guay, L.A., Mmiro, F., Musoke, P., Jackson, J.B., Parkin, N., Eshleman, S.H., 2008. HIV-1 tropism and survival in vertically infected Ugandan infants. J. Infect. Dis. 197, 1382-1388.

Clevestig, P., Pramanik, L., Leitner, T., Ehrnst, A., 2006. CCR5 use by human immunodeficiency virus type 1 is associated closely with the gp120 V3 loop N-linked glycosylation site. J Gen Virol. 87, 607-612.

Cooper, D.A., Heera, J., Goodrich, J., Tawadrous, M., Saag, M., Dejesus, E., Clumeck, N., Walmsley, S., Ting, N., Coakley, E., Reeves, J.D., Reyes-Teran, G., Westby, M., Van Der Ryst, E., Ive, P., Mohapi, L., Mingrone, H., Horban, A., Hackman, F., Sullivan, J., Mayer, H., 2010. Maraviroc versus efavirenz, both in combination with zidovudine-lamivudine, for the treatment of antiretroviral-naive subjects with CCR5-tropic HIV-1 infection. J. Infect. Dis. 201, 803-813.

Department of Health and Human Services, 2009. Guidelines for the use of antiretroviral agents in HIV-1-infected adults and adolescents, pp. 1-161. http://www.aidsinfo.nih.gov/ContentFiles/AdultandAdolescentGL.pdf (last accessed 8.10.10).

Dorr, P., Westby, M., Dobbs, S., Griffin, P., Irvine, B., Macartney, M., Mori, J., Rickett, G., Smith-Burchnell, C., Napier, C., Webster, R., Armour, D., Price, D., Stammen, B., Wood, A., Perros, M., 2005. Maraviroc (UK-427,857), a potent, orally bioavailable, and selective small-molecule inhibitor of chemokine receptor CCR5 with broad-spectrum anti-human immunodeficiency virus type 1 activity. Antimicrob. Agents Chemother. 49, 4721-4732.

Fransen, S., Bridger, G., Whitcomb, J.M., Toma, J., Stawiski, E., Parkin, N., Petropoulos, C.J., Huang, W., 2008. Suppression of dualtropic human immunodeficiency virus type 1 by the CXCR4 antagonist AMD3100 is associated with efficiency of CXCR4 use and baseline virus composition. Antimicrob. Agents Chemother. 52, 2608-2615.

Garaci, E., Aquaro, S., Lapenta, C., Amendola, A., Spada, M., Covaceuszach, S., Perno, C.F., Belardelli, F., 2003. Anti-nerve growth factor Ab abrogates macrophagemediated HIV-1 infection and depletion of CD4+ T lymphocytes in hu-SCID mice. Proc. Natl. Acad. Sci. U.S.A. 100, 8927-8932.

Huang, W., Eshleman, S.H., Toma, J., Fransen, S., Stawiski, E., Paxinos, E.E., Whitcomb, J.M., Young, A.M., Donnell, D., Mmiro, F., Musoke, P., Guay, L.A., Jackson, J.B., Parkin, N.T., Petropoulos, C.J., 2007. Coreceptor tropism in human immunodeficiency virus type 1 subtype D: high prevalence of CXCR4 tropism and heterogeneous composition of viral populations. J. Virol. 81, 7885-7893.

Kupfer, B., Sing, T., Schüffler, P., Hall, R., Kurz, R., McKeown, A., Schneweis, K.E., Eberl, W., Oldenburg, J., Brackmann, H.H., Rockstroh, J.K., Spengler, U., Däumer, M.P., Kaiser, R., Lengauer, T., Matz, B., 2007. Fifteen years of env C2V3C3 evolution in six individuals infected clonally with human immunodeficiency virus type 1 . J. Med. Virol. 79, 1629-1639.

Lihana, R.W., Khamadi, S.A., Lwembe, R.M., Kinyua, J.G., Muriuki, J.K., Lagat, N.J., Okoth, F.A., Makokha, E.P., Songok, E.M., 2009. HIV-1 subtype and viral tropism determination for evaluating antiretroviral therapy options: an analysis of archived Kenyan blood samples. BMC. Infect. Dis. 9, 215-223.

Loftin, L.M., Kienzle, M.F., Yi, Y., Lee, B., Lee, F.H., Gray, L., Gorry, P.R., Collman, R.G., 2010. Constrained use of CCR5 on CD4+ lymphocytes by R5X4 HIV-1: efficiency of Env-CCR5 interactions and low CCR5 expression determine a range of restricted CCR5-mediated entry. Virology 402, 135-148.

Melby, T., Despirito, M., Demasi, R., Heilek-Snyder, G., Greenberg, M.L., Graham, N., 2006. HIV-1 coreceptor use in triple-class treatment-experienced patients: baseline prevalence, correlates, and relationship to enfuvirtide response. J. Infect. Dis. 194, 238-246.

Moyle, G.J., Wildfire, A., Mandalia, S., Mayer, H., Goodrich, J., Whitcomb, J., Gazzard, B.G., 2005. Epidemiology and predictive factors for chemokine receptor use in HIV-1 infection. J. Infect. Dis. 191, 866-872.

Moreno, S., Clotet, B., Sarría, Ortega, E., Leal, Rodriguez-Arrondo, F., Sánchez-de la Rosa, R., Allegro Study Group, 2009. Prevalence of CCR5-tropic HIV1 among treatment-experienced individuals in Spain. HIV Clin. Trials 10, 394-402.

Parameswaran, P., Jalili, R., Tao, L., Shokralla, S., Gharizadeh, B., Ronaghi, M., Fire, A.Z., 2007. A pyrosequencing-tailored nucleotide barcode design unveils opportunities for large-scale sample multiplexing. Nucleic Acids Res. 35, 130-139.

Perno, C.F., Newcomb, F.M., Davis, D.A., Aquaro, S., Humphrey, R.W., Calio, R., Yarchoan, R., 1998. Relative potency of protease inhibitors in monocytes/macrophages acutely and chronically infected with human immunodeficiency virus. J. Infect. Dis. 178, 413-422.

Polz, M.F., Cavanaugh, C.M., 1998. Bias in template-to-product ratios in multitemplate PCR. Appl. Environ. Microbiol. 64, 3724-3730.

Posada, D., Crandall, K.A., 1998. MODELTEST: testing the model of DNA substitution. Bioinformatics $14,817-818$

Princen, K., Schols, D., 2005. HIV chemokine receptor inhibitors as novel anti-HIV drugs. Cytokine Growth Factor Rev. 16, 659-677.
Regoes, R.R., Bonhoeffer, S., 2005. The HIV coreceptor switch: a population dynamical perspective. Trends Microbiol. 13, 269-277.

Rozera, G., Abbate, I., Bruselles, A., Vlassi, C., D’Offizi, G., Narciso, P., Chillemi, G. Prosperi, M., Ippolito, G., Capobianchi, M.R., 2009. Archived HIV-1 minority variants detected by ultra-deep pyrosequencing in provirus may be fully replication competent. AIDS 23, 2541-2543.

Saag, M., Heera, J., Goodrich, J., et al., 2008. Reanalysis of the MERIT study with the enhanced Trofile assay. In: 48th International Conference on Antimicrobial Agents and Chemotherapy (ICAAC 2008), Abstract H-1232a.

Saag, M., Goodrich, J., Fätkenheuer, G., Clotet, B., Clumeck, N., Sullivan, J., Westby M., van der Ryst, E., Mayer, H., 2009. A double-blind. Placebo-controlled trial of maraviroc in treatment-experienced patients infected with Non-R5 HIV-1. J Infect. Dis. 199, 1638-1647.

Scarlatti, G., Tresoldi, E., Bjorndal, A., Fredriksson, R., Colognesi, C., Deng, H.K., Malnati, M.S., Plebani, A., Siccardi, A.G., Littman, D.R., Fenyo, E.M., Lusso, P., 1997 In vivo evolution of HIV-1 co-receptor usage and sensitivity to chemokinemediated suppression. Nat. Med. 3, 1259-1265.

Shepherd, J.C., Jacobson, L.P., Qiao, W., Jamieson, B.D., Phair, J.P., Piazza, P., Quinn, T.C., Margolick, J.B., 2008. Emergence and persistence of CXCR4-tropic HIV-1 in a population of men from the multicenter AIDS cohort study. J. Infect. Dis. 198 1104-1112, 1.

Simon, B., Grabmeier-Pfistershammer, K., Rieger, A., Sarcletti, M., Schmied, B., Puchhammer-Stockl, E., 2010. HIV coreceptor tropism in antiretroviral treatment-naive patients newly diagnosed at a late stage of HIV infection. AIDS 24, 2051-2058.

Symons, J., van Lelyveld, S.F.L., Hoepelman, A.I.M., van Ham, P.M., de Jong, D., Wensing, A.M.J., Nijhuis, M., 2011. Maraviroc is able to inhibit dual-R5 viruses in a dual/mixed HIV-1-infected patient. J. Antimicrob. Chemother., doi:10.1093/jac/dkq535.

Sohy, D., Yano, H., de, N.P., Urizar, E., Guillabert, A., Javitch, J.A., Parmentier, M., Springael, J.Y., 2009. Hetero-oligomerization of CCR2, CCR5, and CXCR4 and the protean effects of "selective" antagonists. J. Biol. Chem. 284, 3127031279.

Swenson, L.C., Dong, W., Mo, T., Woods, C.K., Thielen, A., Jensen, M., et al., 2009. Quantification of HIV Tropism by "Deep" Sequencing Shows a Broad Distribution of Prevalence of X4 Variants in Clinical Samples that Is Associated with Virological Outcome. Presented at CROI 2009, Abstract 680.

Swenson, L.C., Moores, A., Low, A.J., Thielen, A., Dong, W., Woods, C., Jensen, M.A., Wynhoven, B., Chan, D., Glascock, C., Harrigan, P.R., 2010a. Improved detection of CXCR4-using HIV by V3 genotyping: application of population-based and "deep" sequencing to plasma RNA and proviral DNA. J. Acquir. Immune Defic. Syndr. 54 506-510.

Swenson, L.C., Chui, C.K.S, Brumme, C.J., Chan, D., Woods, C.K., Mo, T., et al. $2010 \mathrm{~b}$. Genotypic analysis of V3 in patients experiencing virological failure on maraviroc-containing regimens and correlation with pre-treatment 'deep' sequencing results. Presented at HIV and Hepatitis Drug Resistance Workshop 2010, Abstract 9.

Thielen, A., Sichtig, N., Kaiser, R., Lam, J., Harrigan, P.R., Lengauer, T., 2010. Improved prediction of HIV-1 coreceptor usage with sequence information from the second hypervariable loop of gp120. J. Infect. Dis. 202, 1435-1443.

Toma, J., Whitcomb, J.M., Petropoulos, C.J., Huang, W., 2010. Dual-tropic HIV type 1 isolates vary dramatically in their utilization of CCR5 and CXCR4 coreceptors. AIDS 24, 2181-2186.

Trkola, A., Kuhmann, S.E., Strizki, J.M., Maxwell, E., Ketas, T., Morgan, T., Pugach, P., Xu, S., Wojcik, L., Tagat, J., Palani, A., Shapiro, S., Clader, J.W., McCombie, S., Reyes, G.R., Baroudy, B.M., Moore, J.P., 2002. HIV-1 escape from a small molecule. CCR5specific entry inhibitor does not involve CXCR4 use. Proc. Natl. Acad. Sci. U.S.A. 99, 395-400.

Vandenbroucke, I., Eygen, V.V., Rondelez, E., Vermeiren, H., Baelen, K.V., Stuyver, L.J., 2008. Minor variant detection at different template concentrations in HIV-1 phenotypic and genotypic tropism testing. Open. Virol. J. 2, 8-14.

Vandenbroucke, I., Van, M.H., Mostmans, W., Van, E.V., Rondelez, E., Thys, K., Van, B.K., Fransen, K., Vaira, D., Kabeya, K., De, W.S., Florence, E., Moutschen, M., Vandekerckhove, L., Verhofstede, C., Stuyver, L.J., 2010. HIV-1 V3 envelope deep sequencing for clinical plasma specimens failing in phenotypic tropism assays. AIDS Res. Ther. 7, 4-10.

Wilkin, T.J., Su, Z., Kuritzkes, D.R., Hughes, M., Flexner, C., Gross, R., Coakley, E. Greaves, W., Godfrey, C., Skolnik, P.R., Timpone, J., Rodriguez, B., Gulick, R.M. 2007. HIV type 1 chemokine coreceptor use among antiretroviral-experienced patients screened for a clinical trial of a CCR5 inhibitor: AIDS Clinical Trial Group A5211. Clin. Infect. Dis. 44, 591-595.

Yi, Y., Isaacs, S.N., Williams, D.A., Frank, I., Schols, D., De, C.E., Kolson, D.L., Collman, R.G., 1999. Role of CXCR4 in cell-cell fusion and infection of monocytederived macrophages by primary human immunodeficiency virus type 1 (HIV-1) strains: two distinct mechanisms of HIV-1 dual tropism. J. Virol. 73, 71177125.

Yi, Y., Shaheen, F., Collman, R.G., 2005. Preferential use of CXCR4 by R5X4 human immunodeficiency virus type 1 isolates for infection of primary lymphocytes. J. Virol. 79, 1480-1486. 